\title{
The impact of drug policy liberalisation on willingness to seek help for problem drug use: $A$ comparison of 20 countries
}

Benfer, Isabella; Zahnow, Renee; Barratt, Monica; Maier, Larissa; Winstock, Adam; Ferris, Jason https://researchrepository.rmit.edu.au/esploro/outputs/9921861199901341/filesAndLinks?institution=61RMIT_INST\&index=null

Benfer, I., Zahnow, R., Barratt, M., Maier, L., Winstock, A., \& Ferris, J. (2018). The impact of drug policy liberalisation on willingness to seek help for problem drug use: A comparison of 20 countries. International Journal of Drug Policy, 56, 162-175. https://doi.org/10.1016/j.drugpo.2018.03.032 Document Version: Accepted Manuscript

Published Version: https://doi.org/10.1016/j.drugpo.2018.03.032

Repository homepage: https://researchrepository.rmit.edu.au CC BY-NC-ND V4.0

(C) 2018 Elsevier B.V. All rights reserved.

Downloaded On 2023/04/26 19:39:17 +1000 
Title: The impact of drug policy liberalisation on willingness to seek help for problem drug use: a comparison of 20 countries

*Isabella Benfer ${ }^{\mathrm{a}}$, Dr Renee Zahnow ${ }^{\mathrm{a}}$, Dr Monica J. Barratt ${ }^{\mathrm{b}, \mathrm{c}, \mathrm{d}}$, Dr Larissa Maier ${ }^{\mathrm{e}}$, Dr Adam Winstock $^{\mathrm{f}, \mathrm{g}}$, Dr Jason Ferris ${ }^{\mathrm{a}}$

a Institute for Social Science Research, The University of Queensland, St Lucia, QLD, Australia. Postal address: 80 Meiers Rd, Indooroopilly Queensland 4068 Australia. isabella.benfer@uqconnect.edu.au; r.zahnow@uq.edu.au; j.ferris@uq.edu.au

${ }^{\mathrm{b}}$ Drug Policy Modelling Program, National Drug and Alcohol Research Centre, UNSW, Sydney, NSW, Australia. Postal address: National Drug and Alcohol Research Centre, University of New South Wales, Sydney NSW 2052, Australia.m.barratt@unsw.edu.au

${ }^{c}$ National Drug Research Institute, Faculty of Health Sciences, Curtin University, Perth, WA, Australia. Postal address: GPO Box U1987 Perth WA 6845.

${ }^{\mathrm{d}}$ Behaviours and Health Risks Program, Burnet Institute, Melbourne, VIC, Australia. Postal address: 85 Commercial Road, Melbourne VIC, 3004, Australia.

${ }^{\mathrm{e}}$ University of Zurich, Zurich, Switzerland. Postal address: University of Zurich Rämistrasse $71 \mathrm{CH}-$ 8006 Zürich. larissa.maier@isgf.uzh.ch

${ }_{\mathrm{f}}^{\mathrm{f}}$ Institute of Epidemiology \& Health Care, Faculty of Population Health Sciences, University College London. Postal address: UCL Research Department of Epidemiology \& Public Health, 1 - 19 Torrington Place London WC1E 6BT

${ }^{g}$ Global Drug Survey Ltd, London, UK. Postal address: Global Drug Survey Fergusson House 124/128 City Road London EC1V 2NJ

\section{*Corresponding author}




\begin{abstract}
Background: While the impact of changing drug policies on rates of drug use has been investigated, research into how help-seeking behaviour changes as drug policies become more public-health focused is limited. This paper investigates reported changes in confidence to utilise drug services following hypothetical changes in national drug policy among a sample of individuals who report recent illicit drug use. We predict that liberalising national drug policy will increase the propensity for people who take illegal drugs to utilise health services.
\end{abstract}

Methods: The data were drawn from a sample of self-reported responses to the 2014 Global Drug Survey. Respondents were asked if they would be more confident seeking help if each of the following policy changes were made in their country; a) drugs were legalised; b) penalties for possession of small amounts of drugs were reduced to a fine only; c) drugs were legally available through governments outlets. Multiple correspondence analysis and multinomial logistic regression with post-estimation linear hypothesis testing were conducted.

Results: Individuals residing in countries with relatively liberal drug policy regimes report their helpseeking behaviour is unlikely to change given the hypothetical policy amendments. Individuals from countries with prohibition-based drug policies reported a far greater propensity for changing their help-seeking behaviour in the event of hypothetical policy amendments, citing reduced fear of criminal sanctions as the major reason. Age and sex differences were also found.

Conclusion: The current study demonstrates the capacity for national drug policy reform to influence drug use risk by facilitating or impeding health service engagement among individuals who use illicit substances. We suggest national drug policy requires careful consideration of both prevention goals and the needs of individuals already engaged in illicit substance use; more liberal drug policies may actually encourage the adoption of harm reduction strategies such as health service engagement.

Key words: Comparative policy analysis; Help-seeking behaviour; Harm reduction; Cross-national comparison. 


\section{Introduction}

In the past few decades, there has been a transformative shift in the nature of many countries' drug policies. Harm reduction drug policies are becoming increasingly favoured over more traditional prohibitionist drug policies and call for a drug law reform. Harm reduction policies focus on public health and aim to minimise harms associated with drug use. Effective drug policies require careful consideration of international law, national culture, public health, order and civil liberties; negotiating a balance between these concerns is a major challenge for jurisdictions across the world. Currently, national drug policies tend to favour either a public health or criminal justice approach (Goldberg 2005). Western world countries, in particular, are moving away from traditional prohibition approaches towards harm reduction approaches (Brewley-Taylor et al 2014; Goldberg 2005; Hall 2017; Hurley 2016; Stone 2016).

Throughout the $20^{\text {th }}$ century, in line with international conventions, many countries supported prohibitionist approaches to the supply and use of illicit drugs. Previously even the United Nations (UN) supported this policy approach; in 1990 the United Nations General Assembly Special Session on Drugs (UNGASS) stated the aim of the committee was to protect mankind from drug abuse and trafficking. Just eight years later, in 1998, UNGASS announced that in 10 years' time, the world would be drug-free (Brownstein 2016; Jelsma 2016). The United States (US) led this aggressive 'war on drugs' throughout the 1990s relying on zero tolerance policies that resulted in mass incarcerations while doing little to reduce drug related harms. European countries were the first to adopt harm reduction approaches to drug use after suggestions that prohibition policies were inconsistent with human rights norms (Csete et al 2016) and rising concerns that prohibition policies created a lucrative black market economy that contributed to violence in communities with higher levels of drug use (Csete et al 2016).

Countries such as the Netherlands, Switzerland, Spain and Portugal currently address drug use through pragmatic public health and social inclusion policies and have done since the mid-1990s (International Drug Policy Consortium 2017); Latin American countries began to follow suit towards the beginning of the $21^{\text {st }}$ century (Jelsma 2016). Traditional examples of harm reduction strategies 
include needle exchange programs, opioid substitution therapy, and drug education programs. The decriminalisation of illegal drugs is also a harm reduction strategy because it minimises the potential for negative impacts from a criminal record on the future well-being of people who use drugs. Legalising substances can also reduce the potential for harm through regulated manufacturing that ensures quality control, consistent composition, and transparent information exchange between consumer and supplier. A growing number of countries are adopting drug policy reform to reduce drug-related mortality, health problems, social disorder and disadvantage (Reuter and Trautmann 2009).

The shift in national drug policies, away from prohibition and towards harm reduction, is likely driven by country-level political and economic factors in combination with international pressures from forums such as the European Union (EU) and the UN. For example, upon joining the EU in 1994, Swedish policy-makers responded to pressure from other EU members by abolishing the nation's firm zero-tolerance drug policy and instead implementing a harm reduction regime including needle exchange services and regulated access to some previously prohibited substances through pharmacies (Goldberg 2005). The advent of new drugs (e.g. novel psychoactive substances), changes in supply and purchasing methods (e.g. dark web), cultural and attitudinal shifts, globalisation and an aging population of people who use drugs are just some of the other factors forcing countries to reassess current drug strategies (Berridge 1998; Radimecky 2007). National economies also play an important role in informing policy decisions. Harm reduction policies tend to be more cost effective than criminal justice approaches. In the US alone it is estimated that federal spending on drug control is around \$15 billion annually (Miron \& Waldock 2010; Office of National Drug Control Policy 2010). Harm reduction approaches also have indirect benefits for individuals' future capacity to contribute to society and community health and wellbeing (Csete et al 2016).

Despite evidence of the benefits of harm reduction over prohibition, many countries continue to resist a public health approach to drug use. According to Babor et al, in some countries this resistance stems from long-standing cultural beliefs and social stigma associated with drug use (2009). Other countries face unique challenges to adopting harm reduction approaches such as addressing mass production 
and international supply hubs, lack of appropriately trained professionals and health care resources, endemic drug use and health problems concentrated in stigmatised/discriminated sections of the population (Babor et al 2009). For example, in Mexico, whilst the use of illicit drugs is lower than in many Western countries, drug trafficking is considered a national security problem with consequences for international relations, in particular with the neighbouring US. As such all drug laws are enforced by federal agencies and any changes in drug policy would be highly scrutinised (Babor et al 2009). This example demonstrates that while globally there is a trend towards harm reduction as a more effective and acceptable approach to drug use than prohibition, this should not imply that "one size fits all” (Babor et al 2009). Finally, Babor et al (2009) also encourage that country level characteristics should be taken into account during policy development and implementation.

Variation across countries in individual responses to drug policy is also an important consideration. To assess the capacity of harm reduction policies to achieve public health aims across different national contexts it is necessary to understand how people who use drugs perceive and respond to drug policy changes. One of the main problems with zero tolerance approaches to drug regulation is that they deter people who use drugs from accessing health services (Puras \& Hannah 2017; Godlee \& Hurley 2016; Deryabina \& El-Sadr 2017; Joshua 2017). Harm reduction approaches aim to encourage 'help-seeking' by reducing fear of criminal sanctions, decreasing social stigma and making drug services more accessible for the individuals and their support network. While the capacity for drug policy liberalisation to increase the propensity for individuals who use drugs to engage in helpseeking has been implied in the literature, it has not been investigated empirically (Degenhardt et al 2008; Eastwood et al 2016; Reuter and Stevens 2007).

Help-seeking in the context of drug use can include counselling from family, friends or professionals, being more likely to visit the emergency room following an overdose, accessing needle exchange services for sterile injecting equipment or visiting medical professionals or help centres for support. The propensity for individuals who use drugs to engage in harm reduction by seeking help for their substance use is determined by a coalescence of social, structural, political and individual factors. Structural barriers such as the availability and quality of treatment services and attitudinal barriers, 
including personal beliefs of consumers and their social network about whether or not treatment is necessary or beneficial are arguably two of the biggest impediments to seeking help (Csete et al 2016; Kazatchkine 2017). National drug policies play an integral role in shaping attitudes towards and propensity for help-seeking given that they provide the legislative framework that informs the development of these factors. For example, access to treatment services, particularly for economically and socially disadvantaged people is facilitated by national approaches to drug use that prioritise harm minimisation (Department of Health, 2017). Social stigma and attitudes towards drug use, individuals who use drugs and services aimed at harm reduction are improved through integrated partnerships between government and non-government agencies in areas such as education, health, social welfare and justice; such partnerships can only be achieved under liberalised drug policies that prioritise harm minimisation.

Prohibition policies which impede access to evidence-based treatment for people who use drugs provide a few examples of structural barriers to help-seeking behaviour (Kazatchkine 2017). In this paper, we suggest that the adoption of harm reductist approaches to drug use, as opposed to justice system responses, reduce structural barriers to help-seeking by re-directing resources to service provision. We also argue that the national perspective on drug use plays a significant role in shaping community attitudes towards people who use drugs; reduced stigma, as a result of drug law liberalisation may facilitate engagement with harm minimisation services. Stigma has long been labelled a barrier to treatment by researchers (Marlatt et al 1997). Individuals are less likely to access services if they feel their substance use will be judged poorly by their peers and the community (Marlatt et al 1997). In the United States, where prohibitionist approaches continue to dominant drug policy, citizens tend to express high levels of stigma towards individuals who use drugs. A 2014 John Hopkins study found that Americans have lower opinions of substances use disorders than mental health problems (Barry et al 2014). The criminalisation of common illicit drugs reinforces this stigma. Studies on the effects of drug use and behaviours in Portugal following the decriminalisation of drugs have shown that following the policy change, more people presented to treatment facilities for help 
with drug use problems (Greenwald 2009). This could be ascribed to a harm reduction policy that targeted both structural and attitudinal barriers to help-seeking.

In this study we examine changes in confidence to engage in help-seeking among a sample of individuals who reported recent drug use in the context of three hypothetical, national drug policy changes: a) drugs were legalised; b) penalties for possession of small amounts of drugs were reduced to a fine only; c) drugs were legally available through governments outlets. For reasoned outlined above, we hypothesised that individuals residing in countries where the current drug policy is relatively liberal will report minimal change in their willingness to access health services whereas residents of countries with prohibition drug policies will report significant increases in confidence to seek help for drug related issues in the context of drug policy liberalisation. We stratified the analyses by sex and age because both factors influence drug use, health service engagement and attitudes to drug policies. Rhetoric surrounding harm reduction policies paints a very positive picture of the potential benefits of these approaches for reducing fear of criminal sanctions and subsequently encouraging help-seeking among individuals who use drugs. Evidence shows strategies such as needle and syringe programs and opioid substitution therapy (OTS) services have reduced drug related harms in countries where they have been introduced (Busch et al 2015; Fernandes et al 2017; Abdul-Quader et al 2013; MacArthur et al 2014). What remains unclear is whether or not changes in drug policy at the national level alters individuals' confidence to engage with these types of health services or alternately, whether the individuals who utilise these services represent those who were already confident to seek help. To encourage help-seeking among the very diverse population of individuals who use drugs it is necessary to understand the effectiveness of drug policies for achieving primary aims - reduction in drug-related mortality and morbidity- and the mechanisms through which these aims are met (e.g. engaging in help-seeking).

\section{Methods}

\section{$\underline{\text { Designs and Procedures }}$}


The data was drawn from the 2014 Global Drug Survey (GDS), a cross-sectional online survey developed by academics and experts (for a list of names on the core research team and expert advisory board see https://www.globaldrugsurvey.com/about-us/). The 2014 GDS was conducted between November and December 2013 and was available in 8 languages. The survey was promoted through online media outlets, in magazines, over social media and in newspapers. All responses are anonymous and results were collected from almost 80000 participants. For a more detailed description of the methods of GDS, see Barratt et al 2017. Ethical approval was received from The Psychiatry, Nursing and Midwives Ethics subcommittee at Kings College, London (141/02) as well as from The University of Queensland (No: 2017001452) and The University of New South Wales (HREC HC17769)

\section{$\underline{\text { Participants }}$}

The analytic sample for the current study included all respondents from the 2014 GDS data who met two conditions: 1) the respondent reported they had used an illegal drug (this included cannabis) in the last 12 months; 2) the respondent current resided in one of the 20 selected countries. Adapting previous research looking at country differences around pre-drinking behaviour (Labhart et al 2017) only countries with a minimum of 200 respondents to the survey items of interest were included in the final sample. This minimum benchmark of 200 respondents per country was set to ensure a robust dataset that incorporated countries with both progressive and conservative drug policies.

\section{Measures}

Three items from the GDS 2014 survey formed the key variables of interest in this study. Respondents were asked how prospective policy changes would impact their confidence in help-seeking through the statement - "The change in the law would make me more comfortable about seeking health advice or other support for my drug use" - in relation to the following policies:

Policy a) "If, in your country, possession of small amounts of currently illegal drugs resulted in no penalty whatsoever, how do you think this would change your use of drugs and alcohol? 1-strongly disagree, 5- strongly agree”. 
Policy b) "If, in your country, possession of small amounts of currently illegal drugs resulted in a fine, like a parking ticket, but no criminal record, how do you think this would change your use of drugs and alcohol? 1- strongly disagree, 5- strongly agree."

Policy c) "If currently illicit drugs were legally available through a government outlet, of guaranteed purity and quality, and broadly the same price as now, how would their availability impact on your use of illegal drugs? 1- strongly disagree, 5- strongly agree."

The policy questions also included a range of other statements pertaining to frequency and range of drug use and other questions in the 2014 GDS collected a range of demographic measures including age, gender and country of residence.

We have categorised countries as liberal drug policy regimes or prohibitive drug policy regimes depending on whether the country's current policy adopts a harm reduction or prohibition perspective. The European Monitoring Centre for Drugs and Drug Addiction was a major source used for classifying countries' drug policies (EMCDDA 2018). Countries that have already adopted one or several drug policies that emphasise public health over law enforcement, such as decriminalisation or government outlet programs, were classified as taking a harm reduction approach. Examples include: Portugal, which has decriminalised all drugs; Belgium and the Netherlands which don't tend to prosecute marijuana possession and Switzerland which has decriminalised marijuana. On the other side of the spectrum, countries that have adopted prohibition approaches may have harsher penalties in place for drug users. Such countries include the United States, Australia, New Zealand and the United Kingdom. None of these countries have legalised or decriminalised any illegal drugs for personal consumption apart from some states in the United States that have legalised recreational marijuana. In the middle of the spectrum, there are also countries that have adopted rather disparate drug policies, combining a number of different approaches. This is particularly evident in South American countries such as Colombia in which personal consumption is permitted to a threshold amount although once this threshold is surpassed exceptionally harsh penalties are imposed as users are essentially treated as "dealers". 


\section{Analysis}

Data were analysed using descriptive statistics and ordinal logistic regression models with standard errors clustered by country to compare the differences between country responses, stratified by age and sex. We conducted a Brant test for parallel or proportional odds assumption. For each of the three policy outcomes the test suggested the parallel assumption did not hold (insert your three tests in the Appendix here). Therefore, multiple logistic regression was used to analyse the results and a postestimation linear hypothesis test was employed to test for significance. Multiple correspondence analysis (MCA) was used to explore patterns in confidence for seeking help for drug use by order of age, gender and policy change. Descriptive statistical analysis and multiple correspondence analysis were conducted using the statistical program $\mathrm{R}$ whilst the regression model analyses were conducted using Stata 14.0 (Statacorp 2015).

\section{Results}

The final analytic sample included 36506 respondents from 20 countries ( $74.2 \%$ male; 52\% aged 16$26,35.3 \%$ aged $27-40$ and $12.7 \%$ aged $41-80$. Ages were grouped into these three categories in order for the results to be better visualised by our multiple correspondence analyses. These categories were retained for the multiple logistic regression models in order to maintain consistency. The age categories were determined according to general social definitions of youth, early to mid-adulthood and mid- to late-adulthood. The countries included were Australia, Austria, Brazil, Belgium, Canada, Colombia, Denmark, Ireland, France, Germany, Hungary, Mexico, Netherlands, New Zealand, Portugal, Spain, Sweden, Switzerland, United Kingdom and United States. The 20 countries selected all reached the minimum benchmark set of 200 respondents in each country.

For policy a, countries in which the highest percentage of respondents strongly disagreed that confidence levels would change following drug policy liberalisation were Switzerland (76.1\%), Belgium (50.2\%) and the Netherlands (50.1\%) whilst countries in which the highest percentage of 
responses were 5 (strongly agree) were Sweden (51.6\%), Ireland (35.4\%) and the United Kingdom (33.9\%) (Table 1; Figure 1). Similar results were found for policy $b$ and policy c. For policy b, Switzerland (66.8\%), Belgium (69.3\%) and the Netherlands (67.2\%) remained the top three countries responding strongly disagree whilst Sweden (19.07\%), the United States (18.3\%) and Ireland (17.7\%) were the top three countries strongly agreeing (Table 2; Figure 2). Finally, for policy c, Belgium (51\%), Switzerland (54.5\%) and the Netherlands (50.9\%) remained the top three countries strongly disagreeing that the hypothetical policy change would alter their confidence and Sweden $(62.3 \%)$, Ireland (46.84\%) and the United Kingdom (46.0\%) were the top three countries strongly agreeing with the statement (Table 3; Figure 3).

\section{Multiple correspondence analysis}

Multiple correspondence analysis was conducted to visually explore how country of origin, age, sex and responses to the policy questions were clustered. Figure 4 presents the MCA plot of responses to policy a. This figure highlights the fact that countries with existing liberal drug policy regimes - the Netherlands, Belgium and Switzerland are clustered together around the response of 1 to policy a, indicating little change in confidence. Australia, New Zealand and the United States are clustered around the other end of the plot, more closely associated with the response of 5 to the policy question. The results also indicate that more respondents were male than female and the age-group 16-26 was more associated with a smaller change in confidence to seeking help if drug policies changed.

In Figure 5, the MCA plot for policy b presented very similar results to Figure 4. Countries were clustered in similar groups. Females were shown to be more likely than males to report a change in confidence if drug policies were to change. The model in Figure 6 presents the results for policy c. Again, the Netherlands, Belgium and Switzerland are clustered together around response 1. In this model, males and females are shown as equally likely to respond either way. There is also a large cluster of countries including the United Kingdom, Canada, Hungary, Mexico, Denmark, Brazil and Ireland, all of which are linked with response 5. 
A final model, Figure 7 (supplementary) shows that responses to all policy questions are linked. Those who responded 1 to one question were likely to respond to 1 for the others. Moreover, the arch or horseshoe effect apparent in Figure 4 suggests that the ordered nature of the response options 1 through 5 is valid (Greenacre 1984).

\section{Effects of age and sex}

The results were initially analysed using an ordinal logistic regression model using clustered standard errors. This was in order to observe the effects of age and sex on confidence levels whilst assuming correlation within countries and independence across these clusters. This was followed by a Brant test to test for the parallel assumption. However, the Brant test results showed that this assumption did not hold. Therefore, a multinomial logistic regression model was instead used and post-estimation linear hypothesis tests showed that across all categories, the effects of age and sex were significant. For policy a, the older age groups (27-40 and 41-80) were much less likely to seek help than the 16-26 age group age $\left(\chi^{2}=90.18, \mathrm{df}=8, \mathrm{p}<0.001\right)$. This was also true for policy $\mathrm{b}\left(\chi^{2}=72.47, \mathrm{df}=8, \mathrm{p}<\right.$ $0.001)$ and policy c $\left(\chi^{2}=282.91, \mathrm{df}=8, \mathrm{p}<0.001\right)$. When looking at sex difference, it was found that men were significantly more likely to report confidence change levels of 4-5 (strongly agree) than 1 (strongly disagree) (policy a: $\chi^{2}=70.23, \mathrm{df}=4, \mathrm{p}<0.001$; policy $\mathrm{b}: \chi^{2}=10.89, \mathrm{df}=4, \mathrm{p}<0.05$; policy c: $\chi^{2}=167.71, \mathrm{df}=4, \mathrm{p}<0.001$.

\section{Discussion}

The purpose of this study was to investigate the effect of hypothetical changes in national drug policy on reported changes in confidence in help-seeking among a sample of people who use drugs. The results show that respondents residing in countries that currently adopt more liberal drug policies including Switzerland, Belgium and the Netherlands, tended towards reporting that national policy changes would not make them more confident about seeking help. Individuals residing in Ireland, Sweden, United Kingdom and the United States where current drug policies retain a prohibition stance or changes to policy have been relatively recent and social attitudes towards drug use remain 
negative, were the most likely to report liberalisation of drug policy would increase their confidence in health service engagement. The MCA plots supported this finding. Australia, New Zealand and the United States are co-located with a response of - strongly agree - on the policy questions indicating that drug policy liberalisation who increase confidence in help-seeking among people who use drugs in these countries. People in these countries likely report the greatest improvements in confidence because currently national drug policies in these places are relatively conservative, social attitudes towards drug use remain negative and drug offences incur severe criminal justice penalties.

Another important finding of the current study is that men were more likely to report increased confidence in help-seeking in the context of national drug policy change than women. There is an indication in the literature that men are more confident seeking help for drug use than women largely due to women's greater concern about being socially stigmatised (Kline 1996). Small-scale studies examining the ratio of men to women presenting to drug treatment services also suggest that men are more likely to engage with drug services than women. A study of people who use drugs in the United Kingdom found that the ratio of men to women accessing drug treatment services in England and Wales was approximately 3:1 and in Scotland 2.3:1 (Neale 2004). While there is also widespread evidence that more men use illicit drugs than women, differences in help-seeking behaviour stem from other factors relating to stigma, gender roles and the tendency for drug services to be designed for men thus failing to address the unique needs of women who use drugs (Kline 1996; Ramsey et al 2001). Research has shown that women who inject drugs experience higher mortality rates and drugrelated health problems than their male counterparts (Des Jarlais, Feelemyer, Modi, Arasteh \& Hagan 2012; Roberts, Mathers \& Degenhardt 2010) Experiences of sexual violence from law enforcement and health workers can also deter women from help-seeking (Kline 1996). Women involved in substance abuse are up to five times more likely to experience sexual violence than women in the general population and this violence has been shown to be perpetuated not only by partners but also by law enforcement officers and health workers (Stringer \& Baker 2018; El-Bassel et al 2014; Kline 1996). The UN Special Rapporteur on violence against women has stated that in some countries, women who have committed low-level drug crimes are more likely to receive long prison sentences 
than their male counterparts, even when compared to men who have committed major trafficking offenses (NAME 2013). Our research suggests that changes in national drug policies alone is unlikely to increase women's confidence in help-seeking. Given the findings of the previous studies it is likely that even in the context of drug policy liberalisation more work will be needed to challenge gendered social expectations and develop harm reduction strategies that address the unique needs of women who inject drugs (Copeland and Hall 1992).

Our third and final key finding is that younger individuals are more likely to report that drug liberalisation would increase their confidence in engaging in help-seeking. This finding corresponds with previous research indicating older individuals are less likely be screened for or perceive treatment need for drug use (Kuerbis et al 2014; Choi et al 2014). Key barriers to help-seeking for people who use drugs, including lack of trust in providers, concerns about confidentiality, lack of service approachability and poor access to expertise may be exacerbated by generational differences in perceptions and attitudes towards drug use making it more difficult for older people to access help. As is the case with women who use drugs, changing drug policy and providing services may not be enough to encourage help-seeking among older individuals who use drugs. In addition to the adoption of harm reduction strategies, further efforts to reduce barriers to help-seeking among this group such as improving education and approachability of health service providers may be required (Berridge et al 2017).

\section{Strengths and limitations}

The results of this study need to be considered in the context of several limitations. First, the responses to the policy questions don't necessarily indicate how respondents' behaviour will change given the actual implementation of this policy in their country, merely how they perceive their behaviour will change. An additional limitation is the self-reported nature of the data collected by the GDS. As previously discussed, drug policy regimes are influenced by many factors; these factors also contribute to country level variations in attitudes towards drug use and help-seeking behaviours.

Therefore, a comparison of responses by country needs to keep this in mind. Also, it is important to consider that different countries may implement the same stated policies in different ways. As Ritter 
et al point out, there are typically discrepancies between policies countries state they have adopted and the actual implementation of these policies (Ritter et al 2016).

As most of the data from the 2014 GDS is from European countries, there was not enough data available to look at the responses from Asian countries or those from the Middle East. Further, given that the GDS is self-report and the severity of some of the drug regimes in these countries data accuracy may be problematic in these countries. Despite these limitations, using the GDS provided a unique opportunity to compare reported confidence in help-seeking in 20 countries across 4 continents with a wide range of drug policies from low to high tolerance. Comparing the experiences of individuals who use drugs in countries that have already adopted harm reduction approaches to illicit drug use can inform discussions about drug-policy reform in countries in where political resistance to harm reduction remains.

\section{Conclusions}

National drug policies remain an issue of contention in countries around the world. A multitude of complex, dynamic factors influence the way in which countries develop and implement drug policy and, in turn, the impact of these policies on individuals who use drugs. Harm reduction policies have gained popularity in the last decades with a growing number of countries adopting public health approaches to drug use. In this current period of transformative change in global drug policies, there is a greater need for empirical evidence on the impacts of specific policy responses.

The benefits of harm reduction over prohibition for drug-related mortality and morbidity are well documented. In this study we added to our understanding of approaches to drug policy by exploring the relationship between drug liberalisation and changes in confidence in help-seeking among a sample of individuals who reported recent drug use. The findings provide important insights into the role of sex and age in confidence in help-seeking and suggest a need to tailor strategies to address the unique needs of particular sub-populations of people who use drugs including women and older users. Our comparison of responses by country demonstrates the benefits of harm reduction for facilitating 
confidence in help-seeking by showing the individuals in countries with more liberal approaches to drug use already possess high levels of confidence in engaging with services. 
Conflicts of Interest: Adam Winstock is the founder of the annual Global Drugs Survey. Jason Ferris, Monica Barratt and Larissa Maier are all part of the GDS core research team. For all other authors no conflicts are declared.

Acknowledgements: The authors would like to thank Steffi Cooke for her assistance during preparation of this manuscript. 


\section{References}

Abdul-Quader et al (2013) Effectiveness of Structural-Level Needle/Syringe Programs to Reduce HCV and HIV Infection Among People Who Inject Drugs: A Systematic Review. AIDS Behav $17: 2878-2892$

Barratt, M. J., Ferris, J. A., Zahnow, R., Palamar, J. J., Maier, L. J., \& Winstock, A. R. (2017). Moving on from representativeness: testing the utility of the Global Drug Survey. Substance Abuse: Research and Treatment, 11, 10.1177/1178221817716391.

Barry, C. L., McGinty, E. E., Pescosolido, B., \& Goldman, H. H. (2014). Stigma, Discrimination, Treatment Effectiveness and Policy Support: Comparing Public Views about Drug Addiction with Mental Illness. Psychiatric Services (Washington, D.C.), 65(10), 1269-1272. http://doi.org/10.1176 Berridge, V. (1998). AIDS and Drug Policy; the 1970s or the 1990s?. Drugs: Education, Prevention and Policy, 5(3), 319-321.

Berridge, B. J., McCann, T. V., Cheetham, A., \& Lubman, D. I. (2017). Perceived Barriers and Enablers of Help-Seeking for Substance Use Problems During Adolescence. Health Promotion Practice, 1524839917691944.

Bewley-Taylor, D., Blickman, T., \& Jelsma, M. (2014). The rise and decline of cannabis prohibition. The history of cannabis in the UN drug control system and options for reform. Amsterdam/Swansea: Global Drug Policy Observatory/Transnational Institute.

Busch, M., Grabenhofer-Eggerth, A., Klein, C., \& Weigl, D. M. (2015). Drug related harm reduction in the EU and candidate countries-success and gaps. Epidemiology, Biostatistics and Public Health, 12(1).

Brownstein, H. H. (2016). The Shifting Landscape of Drug Policy and the Need for Innovative Research. Criminology \& Public Policy, 15(3), 837-841. 
Choi, N. G., DiNitto, D. M., \& Marti, C. N. (2014). Treatment use, perceived need, and barriers to seeking treatment for substance abuse and mental health problems among older adults compared to younger adults. Drug and alcohol dependence, 145, 113-120.

Copeland, J., \& Hall, W. (1992). A comparison of women seeking drug and alcohol treatment in a specialist women's and two traditional mixed-sex treatment services. Addiction, 87(9), 1293-1302.

Count the Costs (2013). The War on Drugs: Wasting billions and undermining economies. Retrieved from: http://www.harm-reduction.org/sites/default/files/pdf/The\%20war\%20on\%20drugs $\% 20-\% 20$ wasting $\% 20$ billions $\% 20$ and $\% 20$ undermining $\% 20$ economies $\% 2$ C $\% 20$ Count $\% 20$ the $\% 20$ Costs.pdf Csete, J., Kamarulzaman, A., Kazatchkine, M., Altice, F., Balicki, M., Buxton, J \& Hart, C. (2016). Public Health and International Drug Policy: Report of the Johns Hopkins-Lancet Commission on Drug Policy and Health. Lancet (London, England), 387(10026), 1427.

Degenhardt, L., Chiu, W. T., Sampson, N., Kessler, R. C., Anthony, J. C., Angermeyer, M. \& Karam, A. (2008). Toward a global view of alcohol, tobacco, cannabis, and cocaine use: findings from the WHO World Mental Health Surveys. PLoS medicine, 5(7), e141.

Department of Health (2017). National Drug Strategy 2017-2026. Retrieved from https://www.health.gov.au/internet/main/.../National-Drug-Strategy-2017-2026.docx.

Deryabina, A., \& El-Sadr, W. M. (2017). Uptake of needle and syringe program services in the Kyrgyz Republic: Key barriers and facilitators. Drug \& Alcohol Dependence, 179, 180-186.

Des Jarlais, D. C., Feelemyer, J. P., Modi, S. N., Arasteh, K., \& Hagan, H. (2012). Are females who inject drugs at higher risk for HIV infection than males who inject drugs: an international systematic review of high seroprevalence areas. Drug and Alcohol Dependence, 124(1-2), 95-107. doi:10.1016/j.drugalcdep.2011.12.020.

Eastwood, N., Fox, E., \& Rosmarin, A. (2016). A Quiet Revolution: drug decriminalisation across the globe. London: Release. 
El-Bassel, N., Shaw, S. A., Dasgupta, A., \& Strathdee, S. A. (2014). People Who Inject Drugs in Intimate Relationships: It Takes Two to Combat HIV. Current HIV/AIDS reports, 11(1), 45-51. doi:10.1007/s11904-013-0192-6.

European Monitoring Centre for Drugs and Drug Addiction (2018). Countries. Retrieved from: http://www.emcdda.europa.eu/countries en.

Fernandes, R. M., Cary, M., Duarte, G., Jesus, G., Alarcão, J., Torre, C., ... \& Carneiro, A. V. (2017). Effectiveness of needle and syringe Programmes in people who inject drugs-An overview of systematic reviews. BMC public health, 17(1), 309

Godlee, F., \& Hurley, R. (2016). The war on drugs has failed: doctors should lead calls for drug policy reform. Bmj, 355, i6067.

Goldberg, T. (2005). Will Swedish and Dutch drug policy converge? The role of theory. International Journal of Social Welfare, 14(1), 44-54.

Hall, W. (2017). The future of the international drug control system and national drug prohibitions. Addiction.

Hurley, R. (2016). Consider legalising drugs despite UN treaties, says influential commission. BMJ: British Medical Journal, 353 :i2474.

International Drug Policy Consortium (2017). Western Europe. Retrieved from: http://idpc.net/policyadvocacy/regional-work/western-europe.

Jelsma, M. (2016). UNGASS 2016: Prospects for treaty reform and UN system-wide coherence on drug policy. Journal of Drug Policy Analysis.

Joshua J. (2017) The Legal Framework of the Abuse of Illicit Drugs. In: The Economics of Addictive Behaviours Volume III. Palgrave Macmillan, Cham https://link.springer.com/content/pdf/10.1007\%2F978-3-319-59138-4_7.pdf Kazatchkine, M. (2017). Reasons for drug policy reform: people who use drugs are denied evidence 
based treatment. BMJ: British Medical Journal (Online), 356.

Kline, A. (1996). Pathways into drug user treatment: the influence of gender and racial/ethnic identity.

Substance Use \& Misuse, 31(3), 323-342.

Kuerbis, A., Sacco, P., Blazer, D. G., \& Moore, A. A. (2014). Substance abuse among older adults. Clinics in Geriatric Medicine, 30(3), 629.

Lancaster, K. (2014). Social construction and the evidence-based drug policy endeavour. 
International Journal of Drug Policy, 25(5), 948-951.

MacArthur et al (2014) Interventions to prevent HIV and Hep C in people who inject drugs: A review or reviews to assess evidence of effectiveness. International Journal of drug policy 25(1): 34-52.

Marlatt, G. A., Tucker, J. A., Donovan, D. M., \& Vuchinich, R. E. (1997). Help-seeking by substance abusers: The role of harm reduction and behavioral-economic approaches to facilitate treatment entry and retention. NIDA Res Monogr, 165, 44-84.

Mendiburo-Seguel, A., Vargas, S., Oyanedel, J. C., Torres, F., Vergara, E., \& Hough, M. (2017). Attitudes towards drug policies in Latin America: results from a Latin-American survey. International Journal of Drug Policy, 41, 8-13.

Miron, J. and Waldock, K. (2010). The Budgetary Impact of Ending Drug Prohibition. CATO Institute Paper. Retrieved from: http://www.cato.org/pubs/wtpapers/ DrugProhibitionWP.pdf Neale, J. (2004). Gender and illicit drug use. British Journal of Social Work, 34(6), 851-870.

Office of National Drug Control Policy (2010). National Drug Control Strategy, p. 109. Retrieved from: http://www.whitehouse.gov/sites/default/files/ondcp/policy-and-research/ndcs2010_0.pdf.

Pūras, D., \& Hannah, J. (2017). Reasons for drug policy reform: Prohibition enables systemic human rights abuses and undermines public health. $B M J, 356, \mathrm{i} 6586$.

Radimecký, J. (2007). Rhetoric versus practice in Czech drug policy. Journal of drug issues, 37(1), $11-44$.

Ramsay, M., Baker, P., Goulden, C., Sharp, C., \& Sondhi, A. (2001). Drug misuse declared in 2000: results from the British Crime Survey. London: Home Office Research, Development and Statistics Directorate.

Reuter, P., \& Trautmann, F. (2009). Global illicit drugs markets 1998-2007. Utrecht: European Commission. 
Reuter, P., \& Stevens, A. (2007). An analysis of UK drug policy: A monograph prepared for the UK Drug Policy Commission. UKPDC.

Ritter, A., Livingston, M., Chalmers, J., Berends, L., \& Reuter, P. (2016). Comparative policy analysis for alcohol and drugs: current state of the field. International Journal of Drug Policy, 31, 3950.

Roberts, A., Mathers, B., \& Degenhardt, L. (2010). Women who inject drugs: A review of their risks, experiences and needs. Retrieved from

https://ndarc.med.unsw.edu.au/sites/default/files/ndarc/resources/Women\%20who\%20inject

\section{$\% 20 d r u g s . p d f$}

Sacco, P., Kuerbis, A., Goge, N., \& Bucholz, K. K. (2013). Help seeking for drug and alcohol problems among adults age 50 and older: A comparison of the NLAES and NESARC surveys. Drug and Alcohol Dependence, 131(1), 157-161.

Strang, J., Babor, T., Caulkins, J., Fischer, B., Foxcroft, D., \& Humphreys, K. (2012). Drug policy and the public good: evidence for effective interventions. The Lancet, 379(9810), 71-83.

Stringer, K. L., \& Baker, E. H. (2018). Stigma as a barrier to substance abuse treatment among those with unmet need: An analysis of parenthood and marital status. Journal of family issues, 39(1), 3-27. Stone (2016). The Global State of Harm Reduction 2016. London, United Kingdom: Harm Reduction International.

Taylor, S., Buchanan, J., \& Ayres, T. Prohibition, Privilege and the Drug Apartheid: The failure of drug policy reform to address. International Journal of Drug Policy, 13(5), 397-407.

Verissimo, A. D. O., \& Grella, C. E. (2017). Influence of gender and race/ethnicity on perceived barriers to help-seeking for alcohol or drug problems. Journal of Substance Abuse, 75, 54-61.

Wodak AM, A. (2014). The abject failure of drug prohibition. Australian \& New Zealand Journal of Criminology, 47(2), 190-201. 
Fig. 1. Percentage of people in each country reporting level of confidence change if small amounts of drugs were made legal in their country (Poliy A). Blue = males; Pink= females.

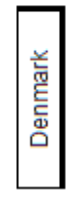

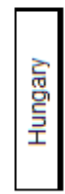

둥

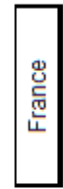

穿

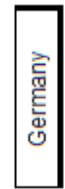

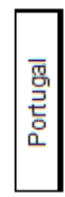

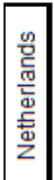
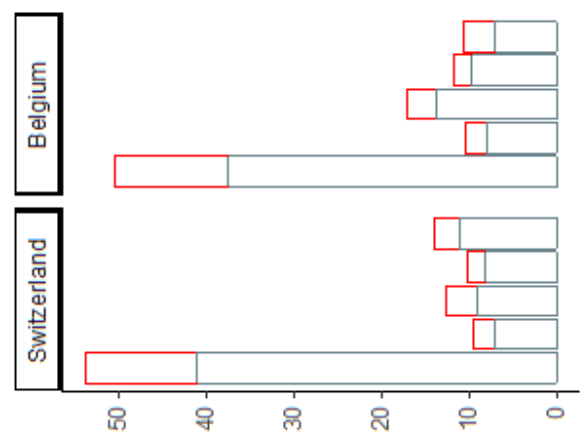

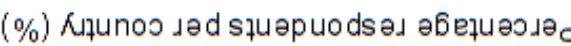
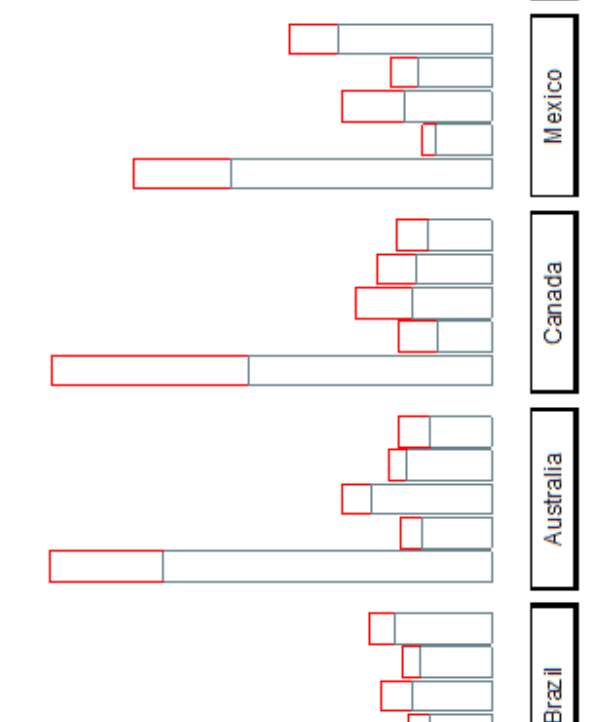

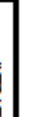

요
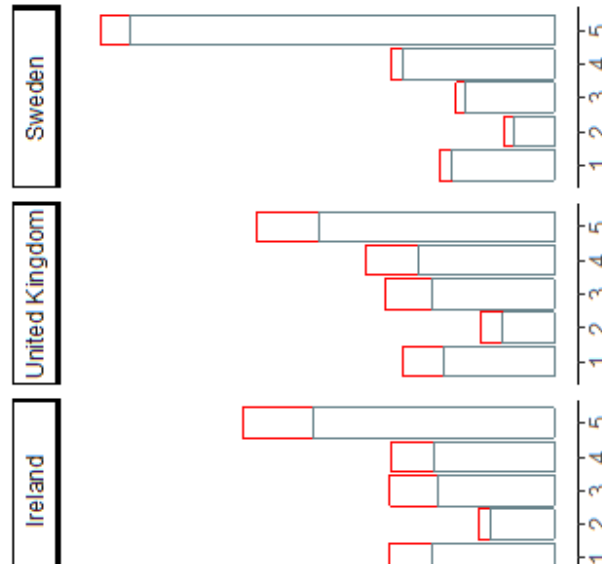

$F-\frac{\pi}{\mathrm{T}}$
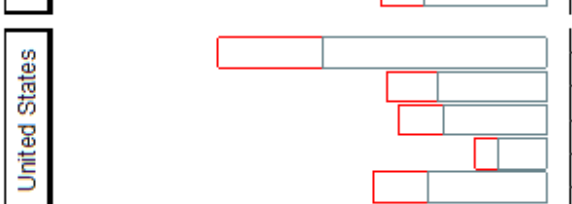

$\rightarrow \frac{10}{2}$

崩

$-\frac{1}{2}$

- 릉

4

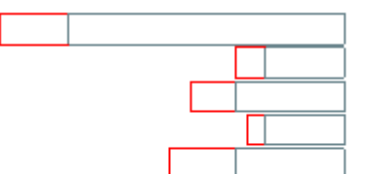

$\begin{array}{lll}-\infty & \frac{n}{c} \\ -\infty & \frac{2}{5} \\ -\infty & \frac{0}{\pi}\end{array}$

$-\overline{\bar{\sigma}}$

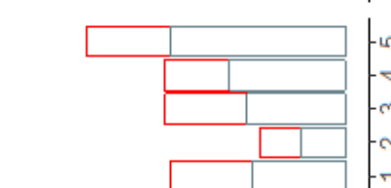

- 10

들 을

늘

-
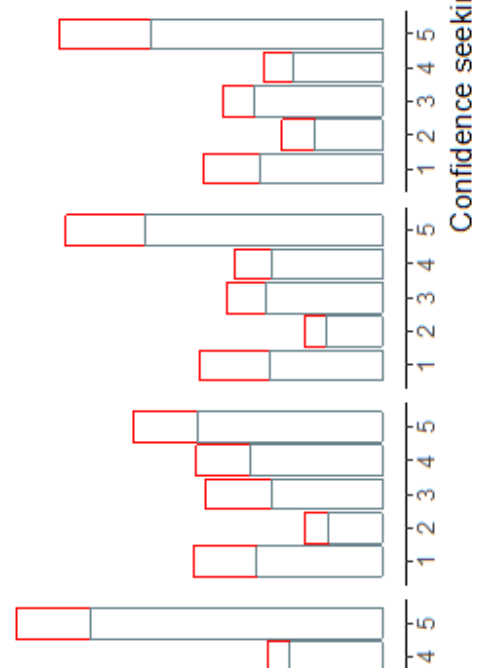

\section{o}

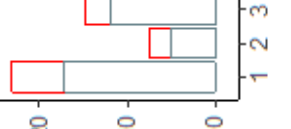


Fig. 2. Percentage of people in each country reporting level of confidence change if only fines apply for possession of illegal drugs (Policy B). Blue $=$ males; Pink $=$ females.

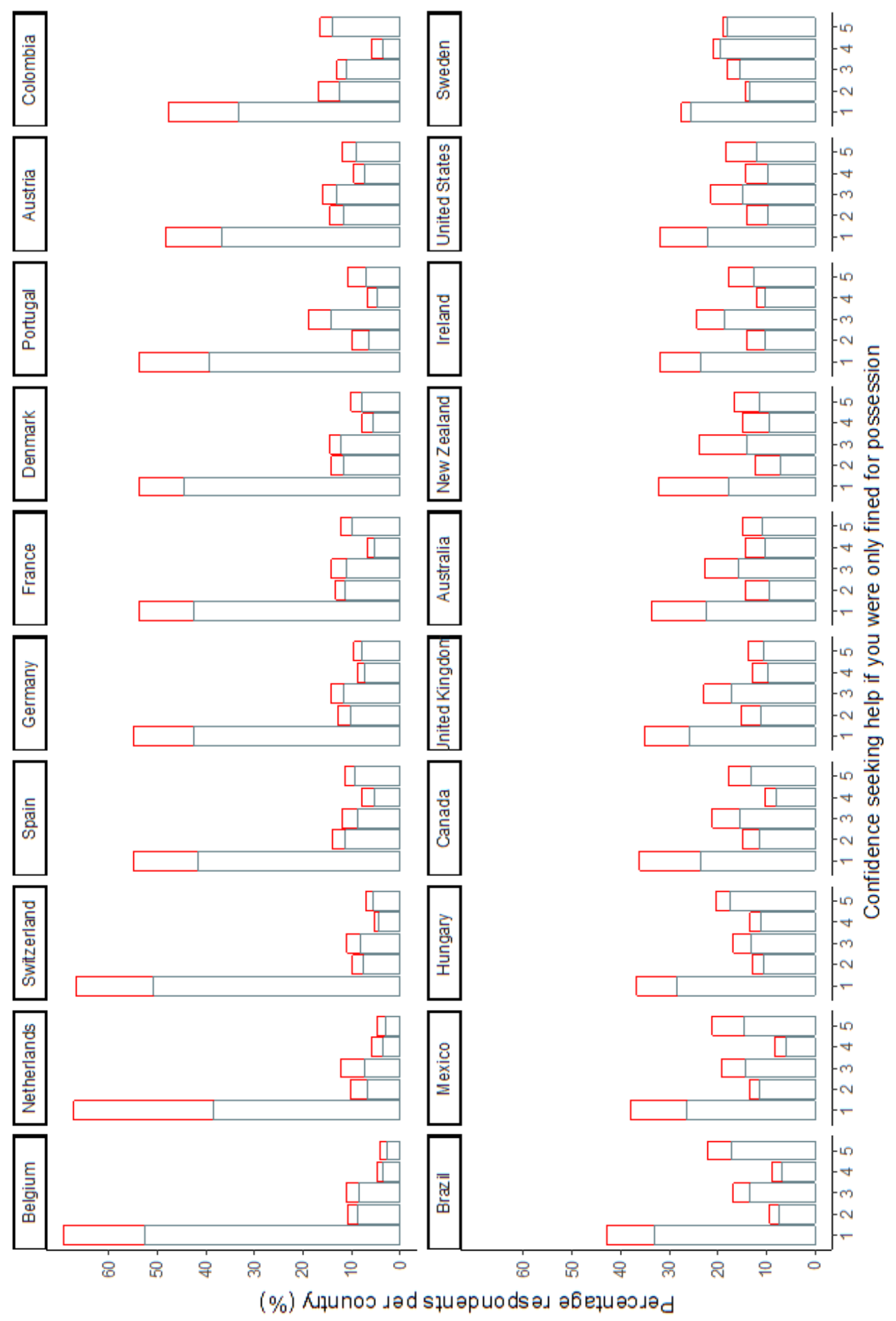


Fig. 3. Policy C: Percentage of people in each country reporting level of confidence change if government outlets were to supply small amounts of drugs. Blue= males; Pink= females.
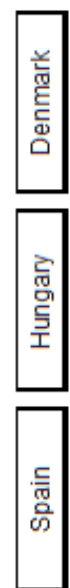

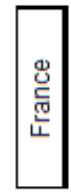

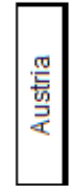

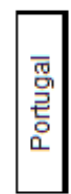

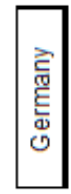

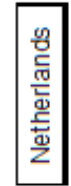
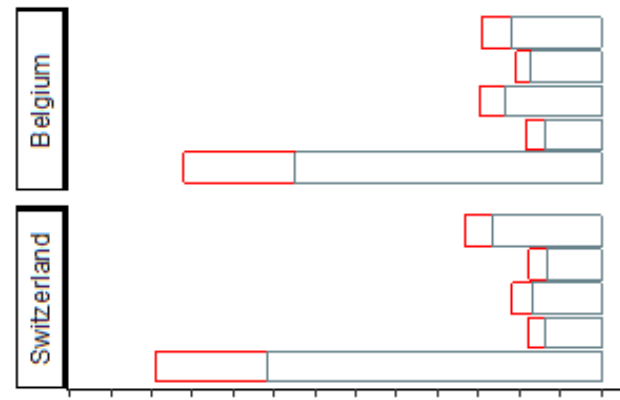

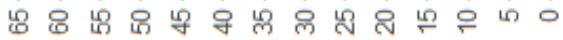
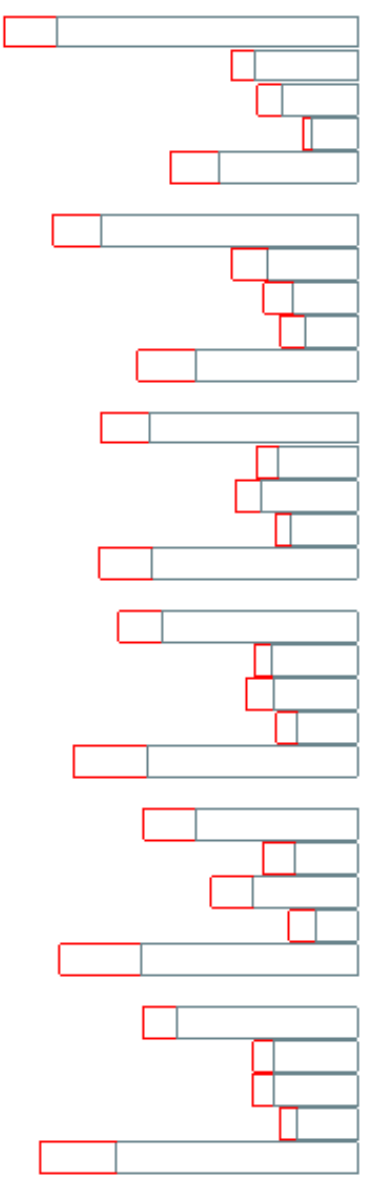
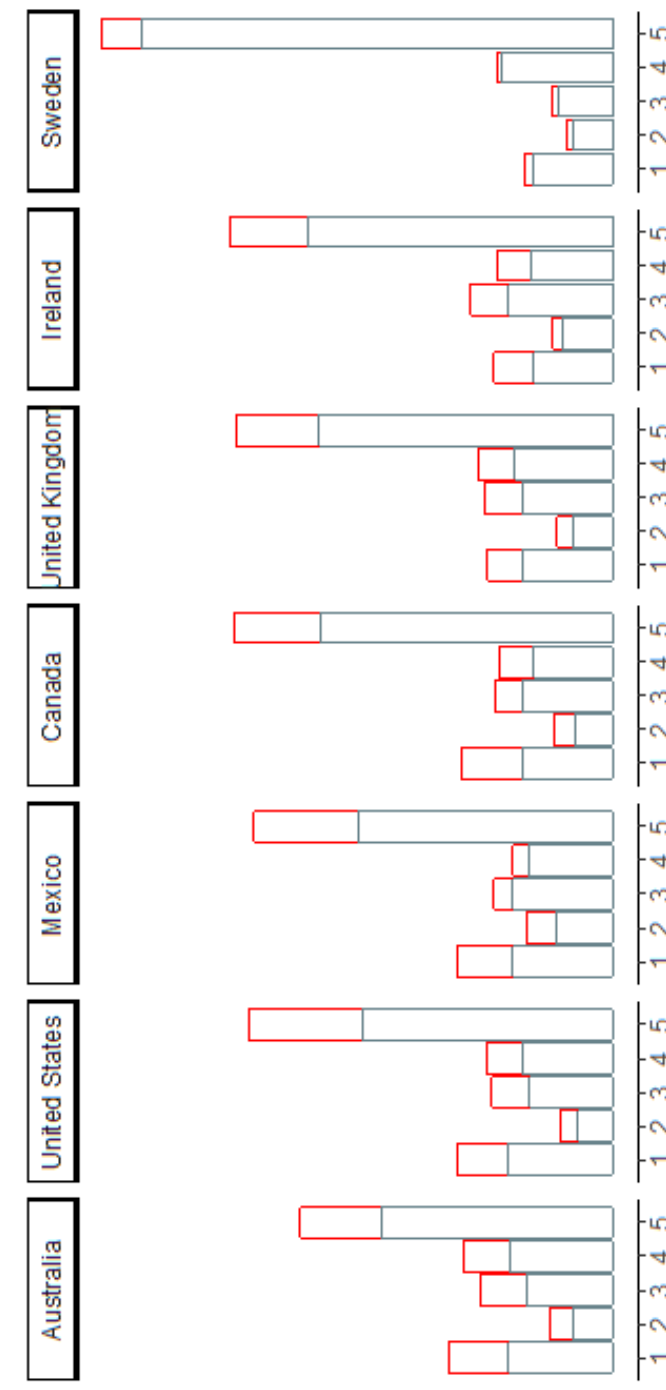

- in

는 능

뭉

$\rightarrow \frac{0}{0}$

n

高

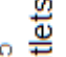
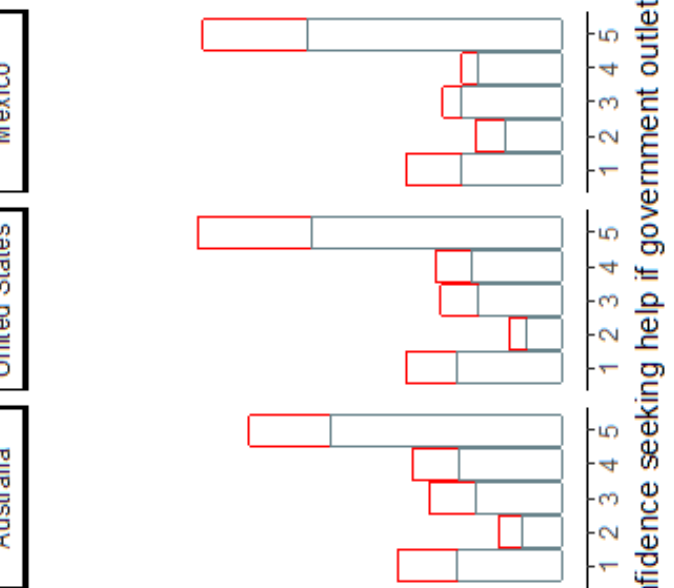

-

$\sim \frac{2}{c}$

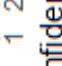
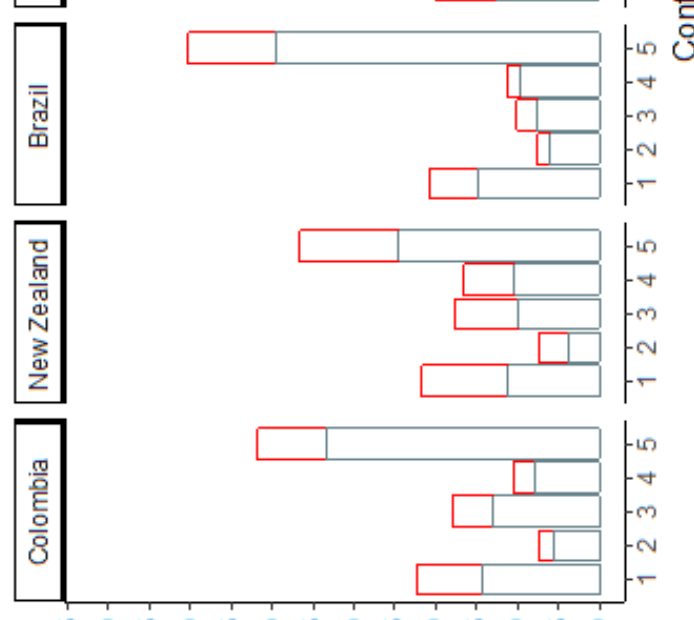

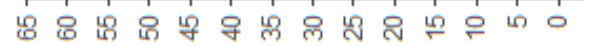

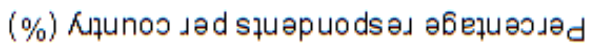




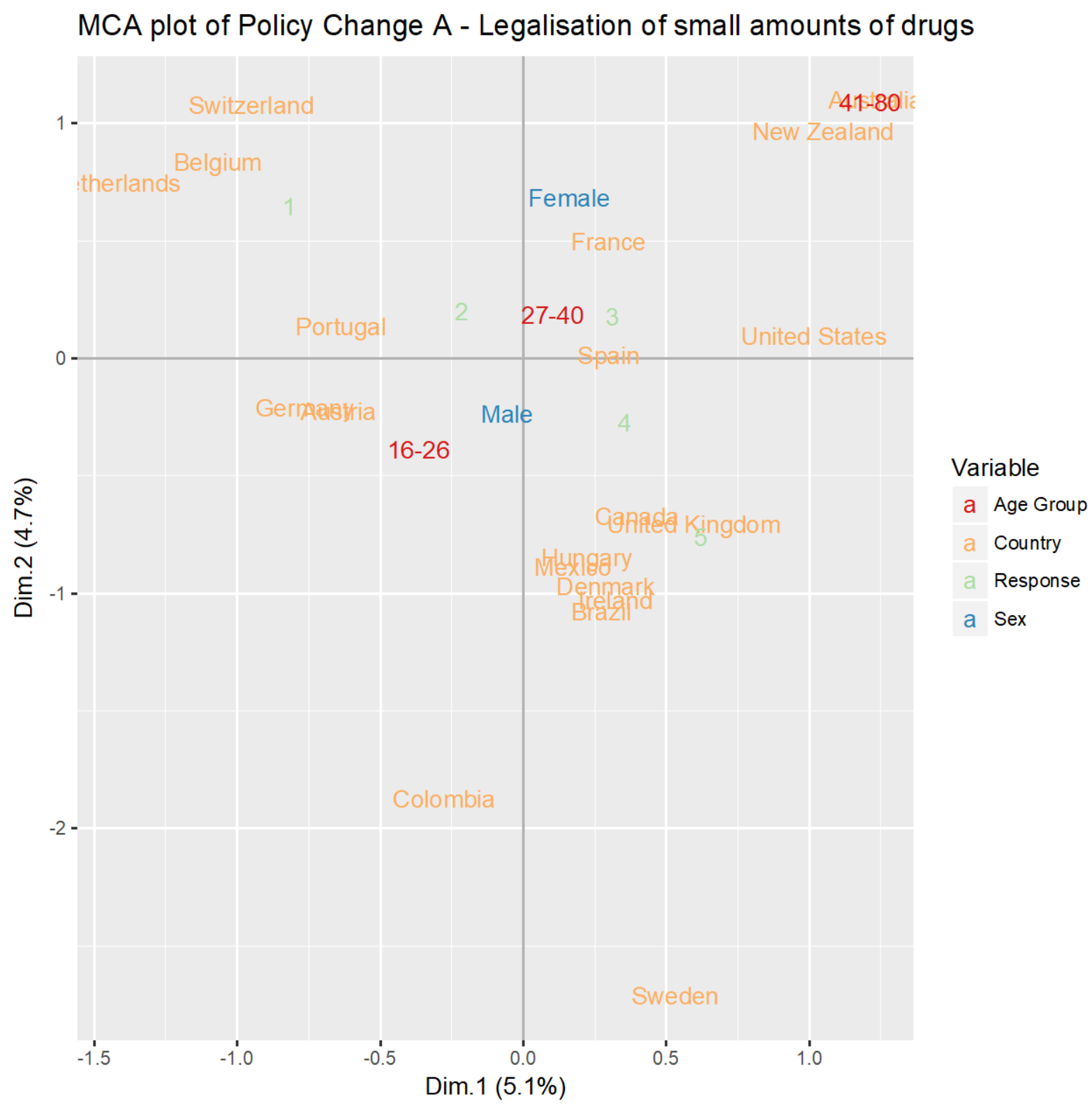

Fig. 4. Multiple correspondence analysis (MCA) of variables in Policy Change A. The variables compared are the 20 country variables, the two sex variables (male and female), the three age variables $(16-26,27-40$ and 41-80) and the five response categories (1-5). Associated variables are grouped closer together whilst negatively correlated variable categories are located in opposed quadrants. The two dimensions on the $\mathrm{x}$ and $\mathrm{y}$ axes explain the total amount of inertia (variability) explained by each dimension. 


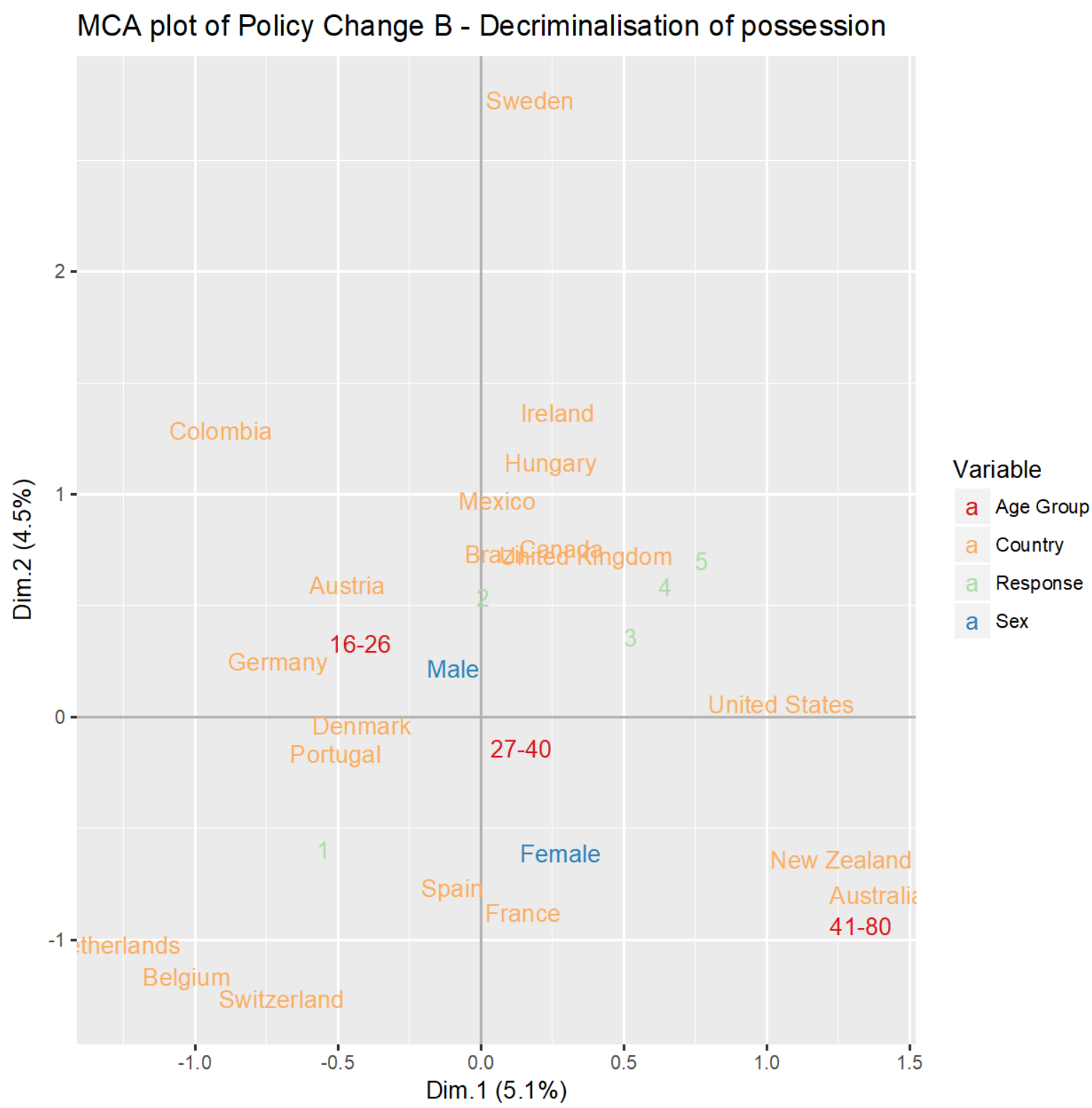

Fig. 5. Multiple correspondence analysis (MCA) of variables in Policy Change B. The variables compared are the 20 country variables, the two sex variables (male and female), the three age variables $(16-26,27-40$ and 41-80) and the five response catogories (1-5). Associated variables are grouped closer together whilst negatively correlated variable categories are located in opposed quadrants. The two dimensions on the $\mathrm{x}$ and $y$ axes explain the total amount of inertia (variability) explained by each dimension. 


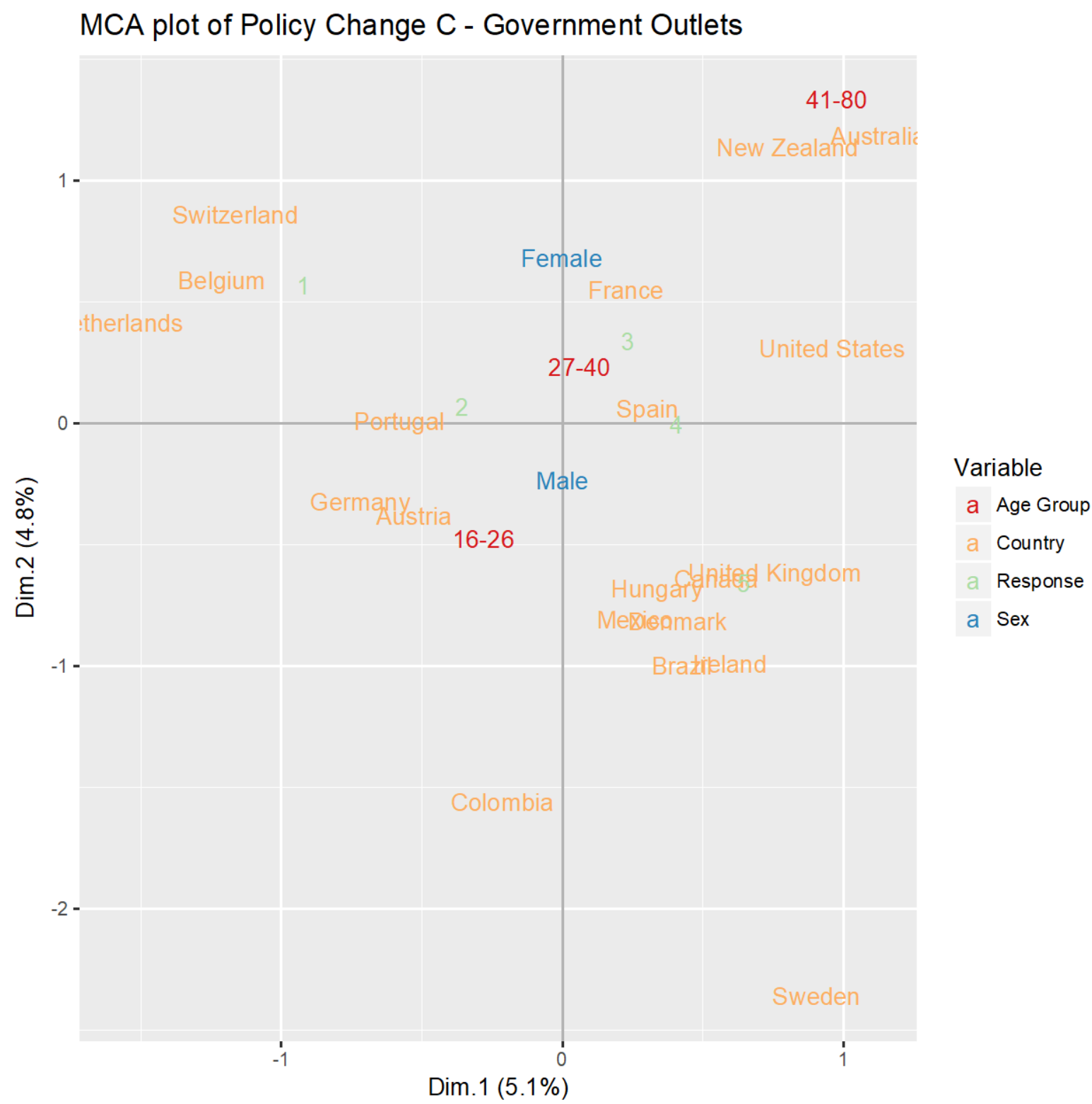

Fig. 6. Multiple correspondence analysis (MCA) of variables in Policy Change C. The variables compared are the 20 country variables, the two sex variables (male and female), the three age variables (16-26, 27-40 and 41-80) and the five response categories (1-5).. Associated variables are grouped closer together whilst negatively correlated variable categories are located in opposed quadrants. The two dimensions on the $\mathrm{x}$ and y axes explain the total amount of inertia (variability) explained by each dimension. 
Tables

Table 1- Policy Change A response breakdown

\begin{tabular}{|c|c|c|c|c|c|c|c|c|}
\hline Country & Policy A Responses $\wedge$ & $\mathrm{n}$ & Total $\%$ & $\%$ Male & $\%$ Female & $\% 16-26^{*}$ & $\% 27-40 *$ & $\% 41-80 *$ \\
\hline \multirow[t]{5}{*}{ Australia } & 1 & 584 & 1.6 & 66.1 & 33.9 & 18.7 & 46.6 & 34.8 \\
\hline & 2 & 241 & 0.7 & 68.0 & 32.0 & 27.0 & 40.2 & 32.8 \\
\hline & 3 & 548 & 1.5 & 62.0 & 38.0 & 24.6 & 48.7 & 26.6 \\
\hline & 4 & 574 & 1.6 & 70.9 & 29.1 & 31.0 & 46.0 & 23.0 \\
\hline & 5 & 770 & 2.1 & 74.2 & 25.8 & 32.9 & 45.3 & 21.8 \\
\hline \multirow[t]{5}{*}{ Austria } & 1 & 272 & 0.7 & 73.2 & 26.8 & 51.8 & 40.1 & 8.1 \\
\hline & 2 & 66 & 0.2 & 80.3 & 19.7 & 56.1 & 40.9 & 3.0 \\
\hline & 3 & 106 & 0.3 & 81.1 & 18.9 & 60.4 & 34.9 & 4.7 \\
\hline & 4 & 111 & 0.3 & 79.3 & 20.7 & 69.4 & 27.9 & 2.7 \\
\hline & 5 & 155 & 0.4 & 81.3 & 18.7 & 61.3 & 32.9 & 5.8 \\
\hline \multirow[t]{5}{*}{ Belgium } & 1 & 649 & 1.8 & 74.3 & 25.7 & 52.4 & 37.6 & 10.0 \\
\hline & 2 & 134 & 0.4 & 76.1 & 23.9 & 65.7 & 30.6 & 3.7 \\
\hline & 3 & 219 & 0.6 & 80.8 & 19.2 & 62.6 & 28.3 & 9.1 \\
\hline & 4 & 151 & 0.4 & 82.8 & 17.2 & 66.2 & 30.5 & 3.3 \\
\hline & 5 & 137 & 0.4 & 65.7 & 34.3 & 54.0 & 35.8 & 10.2 \\
\hline \multirow[t]{5}{*}{ Brazil } & 1 & 135 & 0.4 & 74.1 & 25.9 & 48.1 & 40.0 & 11.9 \\
\hline & 2 & 43 & 0.1 & 67.4 & 32.6 & 58.1 & 37.2 & 4.7 \\
\hline & 3 & 86 & 0.2 & 80.2 & 19.8 & 50.0 & 40.7 & 9.3 \\
\hline & 4 & 76 & 0.2 & 80.3 & 19.7 & 48.7 & 42.1 & 9.2 \\
\hline & 5 & 243 & 0.7 & 79.8 & 20.2 & 53.1 & 41.2 & 5.8 \\
\hline \multirow[t]{5}{*}{ Canada } & 1 & 108 & 0.3 & 61.1 & 38.9 & 45.4 & 35.2 & 19.4 \\
\hline & 2 & 46 & 0.1 & 71.7 & 28.3 & 65.2 & 23.9 & 10.9 \\
\hline & 3 & 92 & 0.3 & 75.0 & 25.0 & 53.3 & 27.2 & 19.6 \\
\hline & 4 & 87 & 0.2 & 74.7 & 25.3 & 46.0 & 41.4 & 12.6 \\
\hline & 5 & 188 & 0.5 & 75.0 & 25.0 & 68.6 & 25.5 & 5.9 \\
\hline \multirow[t]{5}{*}{ Colombia } & 1 & 40 & 0.1 & 62.5 & 37.5 & 70.0 & 27.5 & 2.5 \\
\hline & 2 & 22 & 0.1 & 81.8 & 18.2 & 63.6 & 27.3 & 9.1 \\
\hline & 3 & 35 & 0.1 & 71.4 & 28.6 & 82.9 & 17.1 & 0.0 \\
\hline & 4 & 25 & 0.1 & 72.0 & 28.0 & 92.0 & 4.0 & 4.0 \\
\hline & 5 & 79 & 0.2 & 79.7 & 20.3 & 84.8 & 13.9 & 1.3 \\
\hline \multirow[t]{5}{*}{ Denmark } & 1 & 233 & 0.6 & 80.3 & 19.7 & 45.1 & 41.2 & 13.7 \\
\hline & 2 & 66 & 0.2 & 68.2 & 31.8 & 56.1 & 28.8 & 15.2 \\
\hline & 3 & 165 & 0.5 & 84.2 & 15.8 & 52.7 & 37.0 & 10.3 \\
\hline & 4 & 191 & 0.5 & 86.4 & 13.6 & 54.5 & 36.6 & 8.9 \\
\hline & 5 & 352 & 1.0 & 81.2 & 18.8 & 51.1 & 40.6 & 8.2 \\
\hline \multirow[t]{5}{*}{ France } & 1 & 329 & 0.9 & 77.8 & 22.2 & 35.9 & 39.2 & 24.9 \\
\hline & 2 & 108 & 0.3 & 88.9 & 11.1 & 42.6 & 34.3 & 23.1 \\
\hline & 3 & 164 & 0.4 & 79.9 & 20.1 & 47.6 & 34.1 & 18.3 \\
\hline & 4 & 149 & 0.4 & 79.2 & 20.8 & 46.3 & 30.2 & 23.5 \\
\hline & 5 & 255 & 0.7 & 79.6 & 20.4 & 43.9 & 40.0 & 16.1 \\
\hline \multirow[t]{5}{*}{ Germany } & 1 & 4303 & 11.8 & 76.8 & 23.2 & 54.7 & 37.2 & 8.1 \\
\hline & 2 & 1115 & 3.1 & 76.2 & 23.8 & 62.2 & 32.7 & 5.0 \\
\hline & 3 & 1544 & 4.2 & 80.2 & 19.8 & 63.3 & 32.4 & 4.3 \\
\hline & 4 & 1607 & 4.4 & 83.2 & 16.8 & 63.0 & 32.3 & 4.7 \\
\hline & 5 & 2185 & 6.0 & 82.3 & 17.7 & 66.0 & 29.0 & 5.0 \\
\hline \multirow[t]{5}{*}{ Hungary } & 1 & 363 & 1.0 & 74.9 & 25.1 & 37.2 & 56.2 & 6.6 \\
\hline & 2 & 108 & 0.3 & 80.6 & 19.4 & 49.1 & 41.7 & 9.3 \\
\hline & 3 & 221 & 0.6 & 80.1 & 19.9 & 40.3 & 52.0 & 7.7 \\
\hline & 4 & 279 & 0.8 & 81.7 & 18.3 & 44.1 & 51.3 & 4.7 \\
\hline & 5 & 521 & 1.4 & 84.5 & 15.5 & 45.1 & 49.1 & 5.8 \\
\hline
\end{tabular}




\begin{tabular}{|c|c|c|c|c|c|c|c|c|}
\hline \multirow[t]{5}{*}{ Ireland } & 1 & 92 & 0.3 & 73.9 & 26.1 & 52.2 & 35.9 & 12.0 \\
\hline & 2 & 42 & 0.1 & 85.7 & 14.3 & 59.5 & 28.6 & 11.9 \\
\hline & 3 & 92 & 0.3 & 70.7 & 29.3 & 55.4 & 34.8 & 9.8 \\
\hline & 4 & 91 & 0.2 & 73.6 & 26.4 & 62.6 & 29.7 & 7.7 \\
\hline & 5 & 174 & 0.5 & 77.6 & 22.4 & 55.7 & 37.4 & 6.9 \\
\hline \multirow[t]{5}{*}{ Mexico } & 1 & 77 & 0.2 & 68.8 & 31.2 & 48.1 & 46.8 & 5.2 \\
\hline & 2 & 43 & 0.1 & 67.4 & 32.6 & 58.1 & 39.5 & 2.3 \\
\hline & 3 & 69 & 0.2 & 79.7 & 20.3 & 59.4 & 34.8 & 5.8 \\
\hline & 4 & 51 & 0.1 & 74.5 & 25.5 & 62.7 & 33.3 & 3.9 \\
\hline & 5 & 139 & 0.4 & 71.9 & 28.1 & 52.5 & 38.8 & 8.6 \\
\hline \multirow[t]{5}{*}{ Netherlands } & 1 & 724 & 2.0 & 55.4 & 44.6 & 77.3 & 19.5 & 3.2 \\
\hline & 2 & 153 & 0.4 & 58.2 & 41.8 & 83.0 & 14.4 & 2.6 \\
\hline & 3 & 224 & 0.6 & 58.5 & 41.5 & 78.6 & 18.8 & 2.7 \\
\hline & 4 & 187 & 0.5 & 66.8 & 33.2 & 74.9 & 24.6 & 0.5 \\
\hline & 5 & 157 & 0.4 & 65.6 & 34.4 & 75.2 & 19.1 & 5.7 \\
\hline \multirow[t]{5}{*}{ New Zealand } & 1 & 481 & 1.3 & 52.6 & 47.4 & 32.8 & 38.9 & 28.3 \\
\hline & 2 & 230 & 0.6 & 51.7 & 48.3 & 41.3 & 36.1 & 22.6 \\
\hline & 3 & 494 & 1.4 & 54.5 & 45.5 & 36.0 & 45.7 & 18.2 \\
\hline & 4 & 495 & 1.4 & 64.0 & 36.0 & 39.2 & 39.0 & 21.8 \\
\hline & 5 & 708 & 1.9 & 67.5 & 32.5 & 40.4 & 37.1 & 22.5 \\
\hline \multirow[t]{5}{*}{ Portugal } & 1 & 103 & 0.3 & 72.8 & 27.2 & 58.3 & 33.0 & 8.7 \\
\hline & 2 & 20 & 0.1 & 80.0 & 20.0 & 75.0 & 20.0 & 5.0 \\
\hline & 3 & 43 & 0.1 & 58.1 & 41.9 & 65.1 & 25.6 & 9.3 \\
\hline & 4 & 29 & 0.1 & 72.4 & 27.6 & 51.7 & 41.4 & 6.9 \\
\hline & 5 & 58 & 0.2 & 75.9 & 24.1 & 62.1 & 32.8 & 5.2 \\
\hline \multirow[t]{5}{*}{ Spain } & 1 & 214 & 0.6 & 72.4 & 27.6 & 34.6 & 44.9 & 20.6 \\
\hline & 2 & 67 & 0.2 & 79.1 & 20.9 & 34.3 & 52.2 & 13.4 \\
\hline & 3 & 106 & 0.3 & 74.5 & 25.5 & 45.3 & 38.7 & 16.0 \\
\hline & 4 & 141 & 0.4 & 76.6 & 23.4 & 52.5 & 38.3 & 9.2 \\
\hline & 5 & 218 & 0.6 & 79.8 & 20.2 & 48.6 & 38.5 & 12.8 \\
\hline \multirow[t]{5}{*}{ Sweden } & 1 & 28 & 0.1 & 89.3 & 10.7 & 46.4 & 35.7 & 17.9 \\
\hline & 2 & 12 & 0.0 & 83.3 & 16.7 & 58.3 & 33.3 & 8.3 \\
\hline & 3 & 24 & 0.1 & 91.7 & 8.3 & 62.5 & 29.2 & 8.3 \\
\hline & 4 & 40 & 0.1 & 92.5 & 7.5 & 70.0 & 25.0 & 5.0 \\
\hline & 5 & 111 & 0.3 & 93.7 & 6.3 & 63.1 & 28.8 & 8.1 \\
\hline \multirow[t]{5}{*}{ Switzerland } & 1 & 1104 & 3.0 & 76.1 & 23.9 & 47.2 & 39.9 & 13.0 \\
\hline & 2 & 193 & 0.5 & 75.6 & 24.4 & 53.9 & 36.8 & 9.3 \\
\hline & 3 & 259 & 0.7 & 70.7 & 29.3 & 56.4 & 36.3 & 7.3 \\
\hline & 4 & 210 & 0.6 & 78.6 & 21.4 & 56.7 & 34.3 & 9.0 \\
\hline & 5 & 286 & 0.8 & 79.4 & 20.6 & 53.5 & 33.9 & 12.6 \\
\hline \multirow[t]{5}{*}{ United Kingdom } & 1 & 749 & 2.1 & 73.7 & 26.3 & 43.0 & 36.8 & 20.2 \\
\hline & 2 & 365 & 1.0 & 70.1 & 29.9 & 44.4 & 41.1 & 14.5 \\
\hline & 3 & 843 & 2.3 & 72.4 & 27.6 & 50.9 & 35.1 & 14.0 \\
\hline & 4 & 933 & 2.6 & 72.0 & 28.0 & 56.3 & 32.6 & 11.1 \\
\hline & 5 & 1483 & 4.1 & 78.8 & 21.2 & 56.8 & 32.1 & 11.1 \\
\hline \multirow[t]{5}{*}{ United States } & 1 & 759 & 2.1 & 68.9 & 31.1 & 39.4 & 26.9 & 33.7 \\
\hline & 2 & 310 & 0.8 & 69.0 & 31.0 & 43.2 & 27.1 & 29.7 \\
\hline & 3 & 652 & 1.8 & 69.5 & 30.5 & 42.8 & 32.1 & 25.2 \\
\hline & 4 & 700 & 1.9 & 68.0 & 32.0 & 52.3 & 26.4 & 21.3 \\
\hline & 5 & 1443 & 4.0 & 68.2 & 31.8 & 52.6 & 28.1 & 19.3 \\
\hline
\end{tabular}

${ }^{\wedge}$ Where responses 1-5 correspond to agreement with the following statement: The change in the law would make me more comfortable about seeking health advice or other support for my drug use ( $1=$ strongly disagree and $5=$ strongly agree).

*Age groups 
Table 2 - Policy Change B response breakdown

\begin{tabular}{|c|c|c|c|c|c|c|c|c|}
\hline Country & Policy B Responses $^{\wedge}$ & $\mathrm{n}$ & Total \% & $\%$ Male & $\%$ Female & $\% 16-26^{*}$ & $\% 27-40 *$ & $\% 41-80 *$ \\
\hline \multirow[t]{5}{*}{ Australia } & 1 & 916 & 33.7 & 66.3 & 33.7 & 24.5 & 45.2 & 30.3 \\
\hline & 2 & 391 & 14.4 & 66.0 & 34.0 & 30.9 & 42.5 & 26.6 \\
\hline & 3 & 617 & 22.7 & 69.9 & 30.1 & 27.7 & 48.1 & 24.1 \\
\hline & 4 & 389 & 14.3 & 71.8 & 28.2 & 31.6 & 46.3 & 22.1 \\
\hline & 5 & 404 & 14.9 & 72.5 & 27.5 & 25.0 & 47.5 & 27.5 \\
\hline \multirow[t]{5}{*}{ Austria } & 1 & 342 & 48.2 & 76.3 & 23.7 & 54.1 & 37.4 & 8.5 \\
\hline & 2 & 102 & 14.4 & 81.4 & 18.6 & 59.8 & 36.3 & 3.9 \\
\hline & 3 & 114 & 16.1 & 80.7 & 19.3 & 63.2 & 33.3 & 3.5 \\
\hline & 4 & 68 & 9.6 & 76.5 & 23.5 & 69.1 & 30.9 & 0.0 \\
\hline & 5 & 84 & 11.8 & 76.2 & 23.8 & 58.3 & 36.9 & 4.8 \\
\hline \multirow[t]{5}{*}{ Belgium } & 1 & 895 & 69.4 & 75.8 & 24.2 & 55.8 & 35.3 & 8.9 \\
\hline & 2 & 140 & 10.9 & 79.3 & 20.7 & 66.4 & 29.3 & 4.3 \\
\hline & 3 & 143 & 11.1 & 76.2 & 23.8 & 58.0 & 34.3 & 7.7 \\
\hline & 4 & 60 & 4.7 & 73.3 & 26.7 & 58.3 & 30.0 & 11.7 \\
\hline & 5 & 52 & 4.0 & 65.4 & 34.6 & 55.8 & 34.6 & 9.6 \\
\hline \multirow[t]{5}{*}{ Brazil } & 1 & 250 & 42.9 & 77.2 & 22.8 & 51.2 & 41.2 & 7.6 \\
\hline & 2 & 54 & 9.3 & 79.6 & 20.4 & 53.7 & 31.5 & 14.8 \\
\hline & 3 & 98 & 16.8 & 79.6 & 20.4 & 50.0 & 41.8 & 8.2 \\
\hline & 4 & 52 & 8.9 & 75.0 & 25.0 & 59.6 & 34.6 & 5.8 \\
\hline & 5 & 129 & 22.1 & 77.5 & 22.5 & 48.1 & 45.0 & 7.0 \\
\hline \multirow[t]{5}{*}{ Canada } & 1 & 188 & 36.1 & 65.4 & 34.6 & 53.7 & 29.8 & 16.5 \\
\hline & 2 & 78 & 15.0 & 76.9 & 23.1 & 67.9 & 25.6 & 6.4 \\
\hline & 3 & 110 & 21.1 & 73.6 & 26.4 & 53.6 & 30.9 & 15.5 \\
\hline & 4 & 53 & 10.2 & 77.4 & 22.6 & 45.3 & 45.3 & 9.4 \\
\hline & 5 & 92 & 17.7 & 75.0 & 25.0 & 65.2 & 26.1 & 8.7 \\
\hline \multirow[t]{5}{*}{ Colombia } & 1 & 96 & 47.8 & 69.8 & 30.2 & 77.1 & 20.8 & 2.1 \\
\hline & 2 & 34 & 16.9 & 73.5 & 26.5 & 82.4 & 11.8 & 5.9 \\
\hline & 3 & 26 & 12.9 & 84.6 & 15.4 & 80.8 & 19.2 & 0.0 \\
\hline & 4 & 12 & 6.0 & 58.3 & 41.7 & 83.3 & 8.3 & 8.3 \\
\hline & 5 & 33 & 16.4 & 84.8 & 15.2 & 84.8 & 15.2 & 0.0 \\
\hline \multirow[t]{5}{*}{ Denmark } & 1 & 541 & 53.7 & 82.7 & 17.3 & 49.5 & 38.3 & 12.2 \\
\hline & 2 & 142 & 14.1 & 83.1 & 16.9 & 57.7 & 32.4 & 9.9 \\
\hline & 3 & 145 & 14.4 & 84.1 & 15.9 & 51.7 & 41.4 & 6.9 \\
\hline & 4 & 78 & 7.7 & 70.5 & 29.5 & 57.7 & 37.2 & 5.1 \\
\hline & 5 & 101 & 10.0 & 78.2 & 21.8 & 42.6 & 46.5 & 10.9 \\
\hline \multirow[t]{5}{*}{ France } & 1 & 541 & 53.8 & 79.2 & 20.8 & 39.9 & 37.0 & 23.1 \\
\hline & 2 & 133 & 13.2 & 85.0 & 15.0 & 52.6 & 30.1 & 17.3 \\
\hline & 3 & 142 & 14.1 & 77.5 & 22.5 & 45.1 & 37.3 & 17.6 \\
\hline & 4 & 68 & 6.8 & 79.4 & 20.6 & 48.5 & 32.4 & 19.1 \\
\hline & 5 & 121 & 12.0 & 81.8 & 18.2 & 33.1 & 44.6 & 22.3 \\
\hline \multirow[t]{5}{*}{ Germany } & 1 & 5888 & 54.8 & 77.6 & 22.4 & 56.8 & 36.1 & 7.2 \\
\hline & 2 & 1372 & 12.8 & 80.0 & 20.0 & 66.3 & 29.2 & 4.6 \\
\hline & 3 & 1530 & 14.2 & 80.8 & 19.2 & 64.4 & 32.1 & 3.5 \\
\hline & 4 & 946 & 8.8 & 82.2 & 17.8 & 60.1 & 34.6 & 5.3 \\
\hline & 5 & 1018 & 9.5 & 82.9 & 17.1 & 66.3 & 26.9 & 6.8 \\
\hline \multirow[t]{5}{*}{ Hungary } & 1 & 547 & 36.7 & 77.3 & 22.7 & 40.2 & 52.7 & 7.1 \\
\hline & 2 & 193 & 12.9 & 82.4 & 17.6 & 47.2 & 46.6 & 6.2 \\
\hline & 3 & 250 & 16.8 & 78.4 & 21.6 & 46.8 & 48.8 & 4.4 \\
\hline & 4 & 199 & 13.3 & 83.9 & 16.1 & 45.2 & 48.2 & 6.5 \\
\hline & 5 & 303 & 20.3 & 85.5 & 14.5 & 38.6 & 55.1 & 6.3 \\
\hline Ireland & 1 & 157 & 32.0 & 73.9 & 26.1 & 54.8 & 35.7 & 9.6 \\
\hline
\end{tabular}




\begin{tabular}{|c|c|c|c|c|c|c|c|c|}
\hline & 2 & 69 & 14.1 & 73.9 & 26.1 & 59.4 & 31.9 & 8.7 \\
\hline & 3 & 119 & 24.2 & 77.3 & 22.7 & 59.7 & 32.8 & 7.6 \\
\hline & 4 & 59 & 12.0 & 84.7 & 15.3 & 64.4 & 27.1 & 8.5 \\
\hline & 5 & 87 & 17.7 & 71.3 & 28.7 & 48.3 & 41.4 & 10.3 \\
\hline \multirow[t]{5}{*}{ Mexico } & 1 & 144 & 38.0 & 69.4 & 30.6 & 54.9 & 39.6 & 5.6 \\
\hline & 2 & 51 & 13.5 & 84.3 & 15.7 & 60.8 & 35.3 & 3.9 \\
\hline & 3 & 73 & 19.3 & 74.0 & 26.0 & 54.8 & 39.7 & 5.5 \\
\hline & 4 & 31 & 8.2 & 74.2 & 25.8 & 58.1 & 38.7 & 3.2 \\
\hline & 5 & 80 & 21.1 & 68.8 & 31.2 & 50.0 & 40.0 & 10.0 \\
\hline \multirow[t]{5}{*}{ Netherlands } & 1 & 971 & 67.2 & 57.1 & 42.9 & 77.4 & 19.5 & 3.1 \\
\hline & 2 & 146 & 10.1 & 65.8 & 34.2 & 78.8 & 19.2 & 2.1 \\
\hline & 3 & 176 & 12.2 & 60.2 & 39.8 & 83.5 & 15.9 & 0.6 \\
\hline & 4 & 84 & 5.8 & 59.5 & 40.5 & 75.0 & 23.8 & 1.2 \\
\hline & 5 & 68 & 4.7 & 63.2 & 36.8 & 64.7 & 23.5 & 11.8 \\
\hline \multirow[t]{5}{*}{ New Zealand } & 1 & 774 & 32.1 & 55.4 & 44.6 & 35.1 & 39.0 & 25.8 \\
\hline & 2 & 297 & 12.3 & 56.9 & 43.1 & 44.8 & 35.4 & 19.9 \\
\hline & 3 & 577 & 24.0 & 58.8 & 41.2 & 36.4 & 43.0 & 20.6 \\
\hline & 4 & 357 & 14.8 & 63.0 & 37.0 & 40.3 & 40.1 & 19.6 \\
\hline & 5 & 403 & 16.7 & 68.1 & 31.9 & 37.7 & 38.2 & 24.1 \\
\hline \multirow[t]{5}{*}{ Portugal } & 1 & 136 & 53.8 & 72.8 & 27.2 & 62.5 & 30.9 & 6.6 \\
\hline & 2 & 25 & 9.9 & 64.0 & 36.0 & 80.0 & 20.0 & 0.0 \\
\hline & 3 & 48 & 19.0 & 75.0 & 25.0 & 54.2 & 31.2 & 14.6 \\
\hline & 4 & 17 & 6.7 & 70.6 & 29.4 & 47.1 & 41.2 & 11.8 \\
\hline & 5 & 27 & 10.7 & 66.7 & 33.3 & 55.6 & 40.7 & 3.7 \\
\hline \multirow[t]{5}{*}{ Spain } & 1 & 409 & 54.8 & 75.8 & 24.2 & 40.6 & 43.5 & 15.9 \\
\hline & 2 & 104 & 13.9 & 80.8 & 19.2 & 50.0 & 37.5 & 12.5 \\
\hline & 3 & 89 & 11.9 & 74.2 & 25.8 & 44.9 & 46.1 & 9.0 \\
\hline & 4 & 59 & 7.9 & 67.8 & 32.2 & 49.2 & 44.1 & 6.8 \\
\hline & 5 & 85 & 11.4 & 81.2 & 18.8 & 44.7 & 30.6 & 24.7 \\
\hline \multirow[t]{5}{*}{ Sweden } & 1 & 59 & 27.4 & 93.2 & 6.8 & 50.8 & 32.2 & 16.9 \\
\hline & 2 & 31 & 14.4 & 93.5 & 6.5 & 67.7 & 29.0 & 3.2 \\
\hline & 3 & 39 & 18.1 & 84.6 & 15.4 & 59.0 & 35.9 & 5.1 \\
\hline & 4 & 45 & 20.9 & 93.3 & 6.7 & 75.6 & 22.2 & 2.2 \\
\hline & 5 & 41 & 19.1 & 95.1 & 4.9 & 61.0 & 26.8 & 12.2 \\
\hline \multirow[t]{5}{*}{ Switzerland } & 1 & 1371 & 66.8 & 75.9 & 24.1 & 49.3 & 38.8 & 11.9 \\
\hline & 2 & 201 & 9.8 & 76.1 & 23.9 & 54.2 & 34.8 & 10.9 \\
\hline & 3 & 225 & 11.0 & 74.7 & 25.3 & 52.0 & 39.6 & 8.4 \\
\hline & 4 & 110 & 5.4 & 80.9 & 19.1 & 52.7 & 35.5 & 11.8 \\
\hline & 5 & 145 & 7.1 & 76.7 & 23.3 & 57.2 & 30.3 & 12.4 \\
\hline \multirow[t]{5}{*}{ United Kingdom } & 1 & 1539 & 35.2 & 73.6 & 26.4 & 46.5 & 36.8 & 16.7 \\
\hline & 2 & 667 & 15.3 & 73.6 & 26.4 & 54.6 & 35.5 & 9.9 \\
\hline & 3 & 998 & 22.8 & 75.1 & 24.9 & 54.1 & 32.8 & 13.1 \\
\hline & 4 & 566 & 12.9 & 74.0 & 26.0 & 55.3 & 33.2 & 11.5 \\
\hline & 5 & 603 & 13.8 & 77.4 & 22.6 & 57.7 & 30.3 & 11.9 \\
\hline \multirow[t]{5}{*}{ United States } & 1 & 1235 & 32.0 & 69.5 & 30.5 & 40.2 & 28.9 & 30.9 \\
\hline & 2 & 543 & 14.1 & 68.9 & 31.1 & 51.9 & 27.8 & 20.3 \\
\hline & 3 & 827 & 21.4 & 70.1 & 29.9 & 51.1 & 28.7 & 20.2 \\
\hline & 4 & 550 & 14.2 & 68.5 & 31.5 & 52.2 & 26.2 & 21.6 \\
\hline & 5 & 709 & 18.3 & 65.0 & 35.0 & 49.1 & 28.1 & 22.8 \\
\hline
\end{tabular}

$\wedge$ Where responses 1-5 correspond to agreement with the following statement: The change in the law would make me more comfortable about seeking health advice or other support for my drug use $(1=$ strongly disagree and $5=$ strongly agree).

*Age groups 
Table 3 - Policy Change C response breakdown

\begin{tabular}{|c|c|c|c|c|c|c|c|c|}
\hline Country & Policy C Responses $^{\wedge}$ & $\mathrm{n}$ & Total $\%$ & $\%$ Male & $\%$ Female & $\% 16-26^{*}$ & $\% 27-40 *$ & $\% 41-80 *$ \\
\hline \multirow[t]{5}{*}{ Australia } & 1 & 542 & 19.9 & 63.5 & 36.5 & 16.6 & 44.3 & 39.1 \\
\hline & 2 & 208 & 7.7 & 62.5 & 37.5 & 22.1 & 44.7 & 33.2 \\
\hline & 3 & 437 & 16.1 & 65.7 & 34.3 & 19.9 & 49.0 & 31.1 \\
\hline & 4 & 494 & 18.2 & 68.6 & 31.4 & 28.5 & 47.4 & 24.1 \\
\hline & 5 & 1036 & 38.1 & 74.1 & 25.9 & 36.3 & 45.2 & 18.5 \\
\hline \multirow[t]{5}{*}{ Austria } & 1 & 247 & 34.8 & 74.1 & 25.9 & 53.0 & 38.1 & 8.9 \\
\hline & 2 & 70 & 9.9 & 74.3 & 25.7 & 48.6 & 40.0 & 11.4 \\
\hline & 3 & 97 & 13.7 & 75.3 & 24.7 & 56.7 & 41.2 & 2.1 \\
\hline & 4 & 89 & 12.5 & 83.1 & 16.9 & 68.5 & 31.5 & 0.0 \\
\hline & 5 & 207 & 29.2 & 82.1 & 17.9 & 64.3 & 31.4 & 4.3 \\
\hline \multirow[t]{5}{*}{ Belgium } & 1 & 658 & 51.0 & 73.4 & 26.6 & 52.4 & 37.1 & 10.5 \\
\hline & 2 & 118 & 9.1 & 74.6 & 25.4 & 61.9 & 33.1 & 5.1 \\
\hline & 3 & 191 & 14.8 & 79.6 & 20.4 & 61.3 & 31.4 & 7.3 \\
\hline & 4 & 134 & 10.4 & 82.8 & 17.2 & 64.9 & 30.6 & 4.5 \\
\hline & 5 & 189 & 14.7 & 75.1 & 24.9 & 61.9 & 30.7 & 7.4 \\
\hline \multirow[t]{5}{*}{ Brazil } & 1 & 121 & 20.8 & 71.9 & 28.1 & 47.9 & 37.2 & 14.9 \\
\hline & 2 & 44 & 7.5 & 79.5 & 20.5 & 56.8 & 34.1 & 9.1 \\
\hline & 3 & 59 & 10.1 & 74.6 & 25.4 & 47.5 & 44.1 & 8.5 \\
\hline & 4 & 66 & 11.3 & 84.8 & 15.2 & 45.5 & 45.5 & 9.1 \\
\hline & 5 & 293 & 50.3 & 78.8 & 21.2 & 53.9 & 41.3 & 4.8 \\
\hline \multirow[t]{5}{*}{ Canada } & 1 & 96 & 18.4 & 59.4 & 40.6 & 38.5 & 38.5 & 22.9 \\
\hline & 2 & 37 & 7.1 & 64.9 & 35.1 & 67.6 & 24.3 & 8.1 \\
\hline & 3 & 75 & 14.4 & 76.0 & 24.0 & 54.7 & 26.7 & 18.7 \\
\hline & 4 & 72 & 13.8 & 69.4 & 30.6 & 59.7 & 31.9 & 8.3 \\
\hline & 5 & 241 & 46.3 & 77.2 & 22.8 & 62.7 & 28.6 & 8.7 \\
\hline \multirow[t]{5}{*}{ Colombia } & 1 & 45 & 22.4 & 64.4 & 35.6 & 66.7 & 26.7 & 6.7 \\
\hline & 2 & 15 & 7.5 & 73.3 & 26.7 & 60.0 & 33.3 & 6.7 \\
\hline & 3 & 36 & 17.9 & 72.2 & 27.8 & 88.9 & 11.1 & 0.0 \\
\hline & 4 & 21 & 10.4 & 76.2 & 23.8 & 90.5 & 9.5 & 0.0 \\
\hline & 5 & 84 & 41.8 & 79.8 & 20.2 & 84.5 & 14.3 & 1.2 \\
\hline \multirow[t]{5}{*}{ Denmark } & 1 & 227 & 22.5 & 77.1 & 22.9 & 43.6 & 41.0 & 15.4 \\
\hline & 2 & 58 & 5.8 & 81.0 & 19.0 & 43.1 & 41.4 & 15.5 \\
\hline & 3 & 128 & 12.7 & 75.0 & 25.0 & 46.1 & 41.4 & 12.5 \\
\hline & 4 & 144 & 14.3 & 87.5 & 12.5 & 55.6 & 34.7 & 9.7 \\
\hline & 5 & 450 & 44.7 & 84.0 & 16.0 & 55.6 & 37.6 & 6.9 \\
\hline \multirow[t]{5}{*}{ France } & 1 & 317 & 31.5 & 79.5 & 20.5 & 33.4 & 39.7 & 26.8 \\
\hline & 2 & 100 & 10.0 & 81.0 & 19.0 & 50.0 & 30.0 & 20.0 \\
\hline & 3 & 150 & 14.9 & 79.3 & 20.7 & 44.7 & 36.0 & 19.3 \\
\hline & 4 & 124 & 12.3 & 77.4 & 22.6 & 45.2 & 35.5 & 19.4 \\
\hline & 5 & 314 & 31.2 & 81.5 & 18.5 & 45.9 & 36.6 & 17.5 \\
\hline \multirow[t]{5}{*}{ Germany } & 1 & 4182 & 38.9 & 75.6 & 24.4 & 52.8 & 38.5 & 8.7 \\
\hline & 2 & 1022 & 9.5 & 76.8 & 23.2 & 65.4 & 29.5 & 5.2 \\
\hline & 3 & 1379 & 12.8 & 80.1 & 19.9 & 61.1 & 33.9 & 5.1 \\
\hline & 4 & 1360 & 12.6 & 81.4 & 18.6 & 62.9 & 32.9 & 4.2 \\
\hline & 5 & 2811 & 26.1 & 84.3 & 15.7 & 67.9 & 28.1 & 4.0 \\
\hline \multirow[t]{5}{*}{ Hungary } & 1 & 341 & 22.9 & 73.6 & 26.4 & 34.3 & 56.3 & 9.4 \\
\hline & 2 & 100 & 6.7 & 82.0 & 18.0 & 44.0 & 47.0 & 9.0 \\
\hline & 3 & 181 & 12.1 & 75.7 & 24.3 & 38.7 & 56.4 & 5.0 \\
\hline & 4 & 228 & 15.3 & 81.1 & 18.9 & 47.4 & 47.8 & 4.8 \\
\hline & 5 & 642 & 43.0 & 85.5 & 14.5 & 46.1 & 48.8 & 5.1 \\
\hline
\end{tabular}




\begin{tabular}{|c|c|c|c|c|c|c|c|c|}
\hline \multirow[t]{5}{*}{ Ireland } & 1 & 71 & 14.5 & 66.2 & 33.8 & 47.9 & 39.4 & 12.7 \\
\hline & 2 & 36 & 7.3 & 83.3 & 16.7 & 58.3 & 33.3 & 8.3 \\
\hline & 3 & 85 & 17.3 & 72.9 & 27.1 & 49.4 & 36.5 & 14.1 \\
\hline & 4 & 69 & 14.1 & 71.0 & 29.0 & 62.3 & 30.4 & 7.2 \\
\hline & 5 & 230 & 46.8 & 79.6 & 20.4 & 60.0 & 33.5 & 6.5 \\
\hline \multirow[t]{5}{*}{ Mexico } & 1 & 72 & 19.0 & 63.9 & 36.1 & 48.6 & 44.4 & 6.9 \\
\hline & 2 & 40 & 10.6 & 65.0 & 35.0 & 57.5 & 37.5 & 5.0 \\
\hline & 3 & 55 & 14.5 & 83.6 & 16.4 & 50.9 & 45.5 & 3.6 \\
\hline & 4 & 46 & 12.1 & 84.8 & 15.2 & 73.9 & 21.7 & 4.3 \\
\hline & 5 & 166 & 43.8 & 71.1 & 28.9 & 53.0 & 39.8 & 7.2 \\
\hline \multirow[t]{5}{*}{ Netherlands } & 1 & 736 & 50.9 & 53.8 & 46.2 & 76.9 & 19.7 & 3.4 \\
\hline & 2 & 127 & 8.8 & 61.4 & 38.6 & 81.9 & 17.3 & 0.8 \\
\hline & 3 & 227 & 15.7 & 58.6 & 41.4 & 77.5 & 19.8 & 2.6 \\
\hline & 4 & 150 & 10.4 & 66.0 & 34.0 & 80.0 & 20.0 & 0.0 \\
\hline & 5 & 205 & 14.2 & 69.8 & 30.2 & 75.6 & 19.0 & 5.4 \\
\hline \multirow[t]{5}{*}{ New Zealand } & 1 & 524 & 21.8 & 51.3 & 48.7 & 30.0 & 40.8 & 29.2 \\
\hline & 2 & 178 & 7.4 & 51.7 & 48.3 & 34.3 & 41.6 & 24.2 \\
\hline & 3 & 425 & 17.6 & 55.5 & 44.5 & 35.3 & 43.8 & 20.9 \\
\hline & 4 & 399 & 16.6 & 62.4 & 37.6 & 37.6 & 40.6 & 21.8 \\
\hline & 5 & 882 & 36.6 & 66.9 & 33.1 & 44.6 & 35.8 & 19.6 \\
\hline \multirow[t]{5}{*}{ Portugal } & 1 & 92 & 36.4 & 72.8 & 27.2 & 59.8 & 30.4 & 9.8 \\
\hline & 2 & 21 & 8.3 & 61.9 & 38.1 & 71.4 & 28.6 & 0.0 \\
\hline & 3 & 45 & 17.8 & 71.1 & 28.9 & 60.0 & 31.1 & 8.9 \\
\hline & 4 & 29 & 11.5 & 65.5 & 34.5 & 55.2 & 34.5 & 10.3 \\
\hline & 5 & 66 & 26.1 & 75.8 & 24.2 & 62.1 & 33.3 & 4.5 \\
\hline \multirow[t]{5}{*}{ Spain } & 1 & 200 & 26.8 & 74.0 & 26.0 & 33.5 & 47.5 & 19.0 \\
\hline & 2 & 70 & 9.4 & 68.6 & 31.4 & 42.9 & 37.1 & 20.0 \\
\hline & 3 & 85 & 11.4 & 68.2 & 31.8 & 29.4 & 55.3 & 15.3 \\
\hline & 4 & 114 & 15.3 & 71.1 & 28.9 & 49.1 & 41.2 & 9.6 \\
\hline & 5 & 277 & 37.1 & 84.5 & 15.5 & 53.1 & 34.3 & 12.6 \\
\hline \multirow[t]{5}{*}{ Sweden } & 1 & 23 & 10.7 & 91.3 & 8.7 & 43.5 & 34.8 & 21.7 \\
\hline & 2 & 12 & 5.6 & 83.3 & 16.7 & 41.7 & 50.0 & 8.3 \\
\hline & 3 & 16 & 7.4 & 87.5 & 12.5 & 68.8 & 25.0 & 6.2 \\
\hline & 4 & 30 & 14.0 & 96.7 & 3.3 & 73.3 & 23.3 & 3.3 \\
\hline & 5 & 134 & 62.3 & 92.5 & 7.5 & 63.4 & 28.4 & 8.2 \\
\hline \multirow[t]{5}{*}{ Switzerland } & 1 & 1119 & 54.5 & 74.9 & 25.1 & 48.5 & 38.4 & 13.0 \\
\hline & 2 & 185 & 9.0 & 75.7 & 24.3 & 53.5 & 36.2 & 10.3 \\
\hline & 3 & 225 & 11.0 & 76.9 & 23.1 & 53.8 & 37.8 & 8.4 \\
\hline & 4 & 181 & 8.8 & 75.7 & 24.3 & 56.4 & 37.0 & 6.6 \\
\hline & 5 & 342 & 16.7 & 79.8 & 20.2 & 52.0 & 36.5 & 11.4 \\
\hline \multirow[t]{5}{*}{ United Kingdom } & 1 & 668 & 15.3 & 71.6 & 28.4 & 38.2 & 39.5 & 22.3 \\
\hline & 2 & 294 & 6.7 & 70.7 & 29.3 & 46.3 & 38.4 & 15.3 \\
\hline & 3 & 681 & 15.6 & 70.3 & 29.7 & 46.8 & 38.2 & 15.0 \\
\hline & 4 & 719 & 16.4 & 72.6 & 27.4 & 50.2 & 35.3 & 14.5 \\
\hline & 5 & 2011 & 46.0 & 78.1 & 21.9 & 60.1 & 30.4 & 9.5 \\
\hline \multirow[t]{5}{*}{ United States } & 1 & 736 & 19.0 & 67.1 & 32.9 & 33.4 & 29.9 & 36.7 \\
\hline & 2 & 245 & 6.3 & 66.1 & 33.9 & 43.3 & 28.2 & 28.6 \\
\hline & 3 & 570 & 14.8 & 68.2 & 31.8 & 43.0 & 28.9 & 28.1 \\
\hline & 4 & 595 & 15.4 & 71.8 & 28.2 & 43.5 & 31.3 & 25.2 \\
\hline & 5 & 1718 & 44.5 & 68.6 & 31.4 & 57.1 & 26.1 & 16.8 \\
\hline
\end{tabular}




\section{Supplementary Figures}

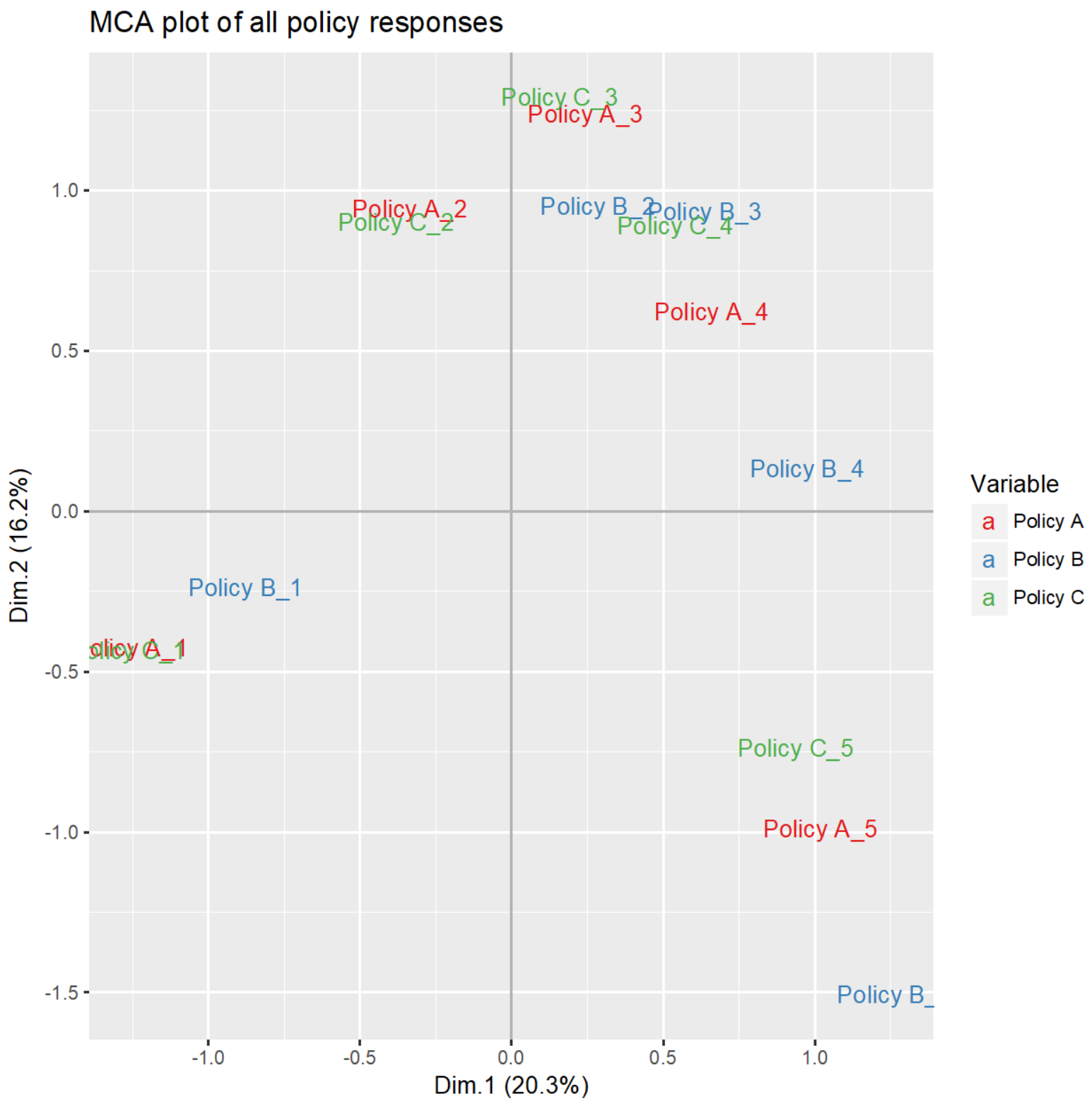

Fig. 7. Multiple correspondence analysis (MCA) of the responses to Policy Changes A, B and C. 


\section{Appendix 1}

\section{Brant test results:}

Policy A: $\chi^{2}=23.77, \rho<0.001,6$; Policy B: $\chi^{2}=63.00, \rho<0.000,6$; Policy C: $\chi^{2}=36.01, \rho<0.000$, 6

Table 1a: Ordinal regression model results for Policy A

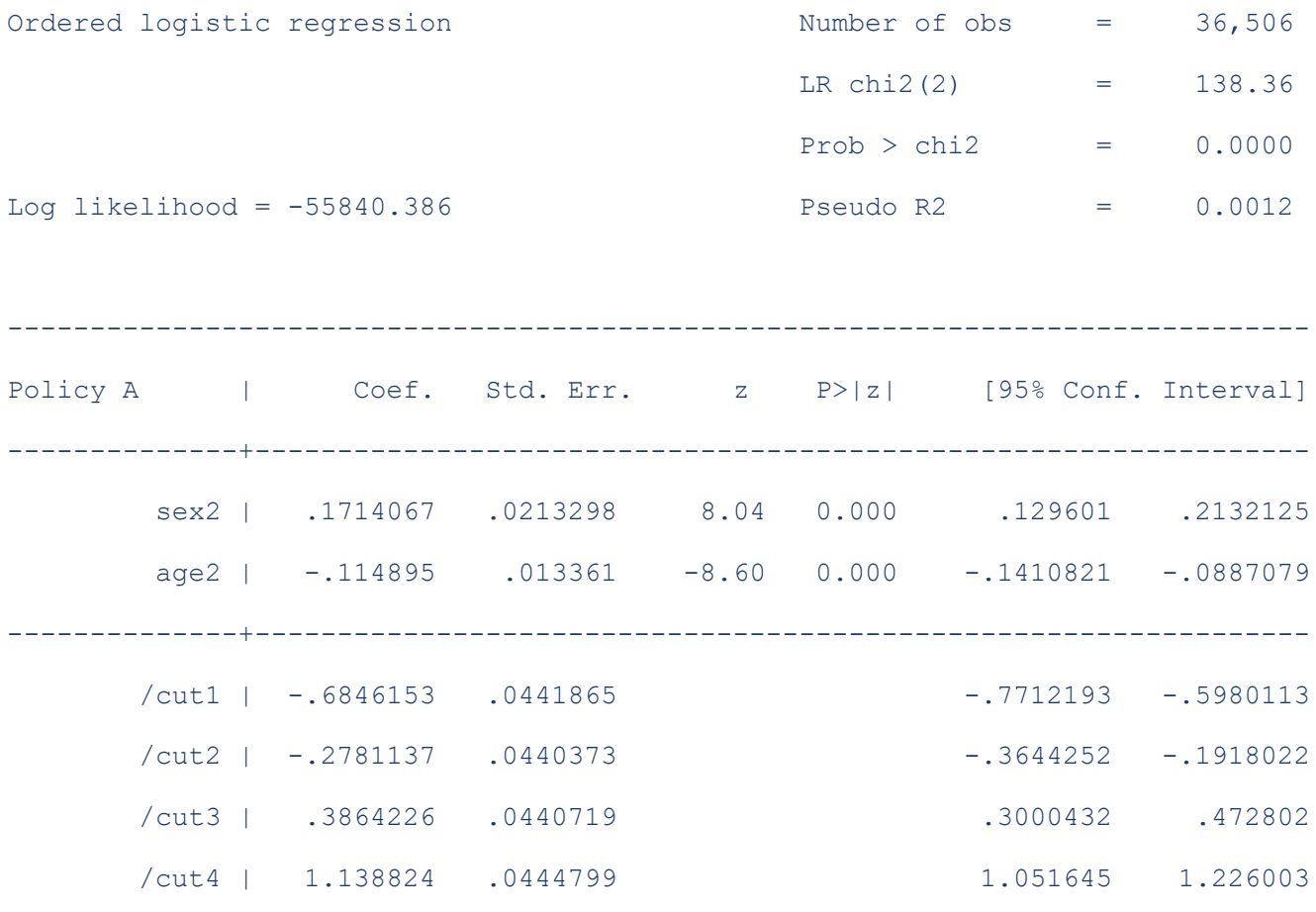

Table 1b: Ordinal regression model results for Policy B

$\begin{array}{llr}\text { Ordered logistic regression } & \text { Number of obs } & 36,506 \\ & \text { LR chi2(2) } & 11.58 \\ & \text { Prob > chi2 } & 0.0031 \\ \text { Log likelihood }=-51914.522 & \text { Pseudo R2 } & 0.0001\end{array}$

Policy B | Coef. Std. Err. [ $\quad$ z $\quad$ P $>|z|$ Conf. Interval] 


\begin{tabular}{rrrrrrr} 
sex2 | & .0649549 & .0220312 & 2.95 & 0.003 & .0217745 & .1081352 \\
age2 | | & -.023301 & .0137981 & -1.69 & 0.091 & -.0503447 & .0037428 \\
\hline /cut1 | & -.0617143 & .0454998 & & -.1508924 & .0274637 \\
/ cut2 | & .4665282 & .0455472 & .3772573 & .5557992 \\
/ cut3 | & 1.285752 & .0460381 & 1.195519 & 1.375985 \\
/ cut4 I & 2.016666 & .0470995 & 1.924353 & 2.10898
\end{tabular}

$\underline{\text { Table 1c: Ordinal regression model results for Policy C }}$

$\begin{array}{llr}\text { Ordered logistic regression } & \text { Number of obs } & 36,506 \\ & \text { LR chi2(2) } & 414.70 \\ & \text { Prob }>\text { chi2 } & 0.0000 \\ \text { Log likelihood }=-53925.005 & \text { Pseudo R2 } & 0.0038\end{array}$

\begin{tabular}{|c|c|c|c|c|c|c|c|c|}
\hline Policy & 3 & I & Coef. & Std. Err. & $z$ & $\mathrm{P}>|\mathrm{z}|$ & [95\% Conf. & Interval] \\
\hline & $\operatorname{sex} 2$ & । & .2726207 & .0214994 & 12.68 & 0.000 & .2304827 & .3147587 \\
\hline & age2 & I & -.2147108 & .0134505 & -15.96 & 0.000 & -.2410733 & -.1883483 \\
\hline & / cut 1 & I & -.7166399 & .044457 & & & -.8037741 & -.6295057 \\
\hline & / cut2 & 1 & -.350325 & .0443197 & & & -.4371901 & -.26346 \\
\hline & $1 \operatorname{cut} 3$ & 1 & .2272627 & .044316 & & & .140405 & .3141204 \\
\hline & / cut 4 & 1 & .8123201 & .0445209 & & & .7250608 & .8995794 \\
\hline
\end{tabular}

